\title{
Dynamic investigation of a large historical cathedral
}

\author{
Ahmed Elyamani ${ }^{1, *}, \dagger$, Oriol Caselles ${ }^{2}$, Pere Roca ${ }^{3}$ and Jaime Clapes ${ }^{2}$ \\ ${ }^{1}$ Department of Archaeological Conservation, Faculty of Archaeology, Cairo University, Giza, Egypt \\ ${ }^{2}$ Department of Geotechnical Engineering and Geo-Sciences, Technical University of Catalonia, Barcelona, Spain \\ ${ }^{3}$ Department of Construction Engineering, Technical University of Catalonia, Barcelona, Spain
}

\begin{abstract}
1. SUMMARY
The presented research aimed at studying the dynamic behavior of Mallorca cathedral (Mallorca Island, Spain) under ambient sources of vibration and seismic events. The cathedral is one of the greatest built masonry structures worldwide. It is characterized for its audacious dimensions and slender structural members. Because of it, its dynamic the study of its dynamic behavior is a clear concern. The cathedral dynamic properties were firstly identified using Ambient Vibration Testing (AVT). Afterwards, a dynamic monitoring system was implemented to continuously measure, record, and wirelessly transfer the acceleration records without having to set up an activating threshold. This monitoring type was implemented because of the low seismic intensity of Mallorca Island with a basic ground acceleration of only $0,04 \mathrm{~g}$ according to the Spanish seismic standard. The continuous monitoring allowed for capturing some seismic events and some drops in the natural frequencies were noticed due to a breathing crack effect. Using both AVT and the continuous monitoring system, global modes could be more accurately identified than more local ones. The identification of the global modes was more attainable than in the case of more local ones. The temperature was a more influential environmental parameter than humidity and wind for all of the identified modes except for one more directly depended on wind.
\end{abstract}

\section{INTRODUCTION}

Dynamic investigation of structures, whether modern or historic, includes two interconnected activities; these are the dynamic identification and the dynamic monitoring. Usually, before installing a dynamic monitoring system in a structure, dynamic identification tests are carried out. In some cases, due to economic reasons, for instance, only the first activity is performed to obtain an acceptable insight about the dynamic characteristics of the structure.

Dynamic identification of historic structures is carried out to achieve some or all of the following aims : 1) to obtain information on the global dynamic behavior of the structure, including natural frequencies, mode shapes and damping coefficients, 2) to validate and update a structure's numerical model by comparing experimental and numerical natural frequencies and mode shapes, 3) to assess the level of connection between different parts, in specific, assess the level of connection between parts partially separated by cracks, 4) to identify weak structural features, 5) to study the influence of major damage on the structural response, 6) to evaluate the effect of possible repair and 
strengthening solutions by comparing the dynamic parameters before and after the intervention and hence improving the design for future applications in other similar structures, 7) to allow monitoring before (diagnosis phase) and after the intervention (post-intervention control phase) by repeating periodically the dynamic tests and comparing the results, and 8) to help in the optimal selection of strategic locations of sensors for the following activity, if needed, of dynamic monitoring. Some of the early applications of dynamic identification in studying historic structures can be consulted at [1-3]. For recent applications, the reader is referred to [4-9].

Similar to the dynamic identification, dynamic monitoring is carried out to achieve the following two objectives: to obtain information on the global dynamic behavior of a historical structure and to validate and update a historical structure's numerical model. In addition, dynamic monitoring may also aim at achieving the following purposes: 1) to study the evolution of modal parameters in time, thus evaluating quantitatively the progression of the damage pattern (structural health monitoring); 2) to study the influence of environmental climatic effects (temperature, humidity, etc.) on the dynamic parameters; 3 ) to capture the dynamic response in the occasion of possible seismic events, the measured accelerations in this case are expected to be higher than those measured in AVT by several orders of magnitude, therefore proving a better possibility to characterize the structure's modal parameters; 4) to verify the effectiveness of any possible intervention, before the execution, the dynamic monitoring can work as an early warning system to detect the need for any urgent intervention, during the execution, it can provide warning procedures contributing to the safety of the personnel involved, after the execution, by comparing the dynamic parameters before and after the intervention, it is possible to evaluate its effectiveness, and 5) to perform verification and long term control within a long-term maintenance program.

Contrary to the large available number of publications on dynamic identification of historic structures, only few publications exist for dynamic monitoring studies [10]. Some recent applications have been presented by [11-12].

This paper presents a part of a wider research aimed at contributing to the methodological approaches adopted for the seismic assessment of large historic structures. Mallorca cathedral, a large medieval construction, has been adopted as a case study. In many cases, and due to the complexity of the knowledge about the assessed historic structure, it is essential to combine different approaches, such as historical investigation, inspection, experiments, monitoring and structural analysis, in the study of historical structures. The aim is to minimize any possibly required seismic strengthening interventions (minimum intervention concept) by increasing the level of knowledge about the structure. In the presented research, the employed experimental investigation activities were the dynamic identification tests and the dynamic monitoring.

Most approaches for dynamic monitoring are based on the use of a threshold limit which is used to trigger the system when the parameters measured surpass the limit. Here, an alternative is considered that consists of a continuous monitoring system based on the permanent measurement of the ambient vibration. It was decided to implement this type of monitoring because the amplitude of the seismic motion expected in the island of Mallorca is low. According to the Spanish code for seismic design [13], the basic seismic acceleration in Mallorca Island is only $0.04 \mathrm{~g}$.

The monitoring results presented here could be successfully integrated with the numerical modeling in order to calibrate and validate the structural models presented for the analysis of the cathedral. This integration of monitoring and structural analysis 
included two main features. On one hand, tentative structural analyses were carried out to identify important aspects of the dynamic tests and monitoring strategies such as critical points of the structure where to place the sensors. On the other hand, the results of the dynamic investigation were used to perform model updating until obtaining a satisfactory structural model adequately matching the measured dynamic properties of the structure. Once the structural model had been validated, it was used to carry out the seismic assessment of the structure [14].

\section{ABOUT MALLORCA CATHEDRAL}

Mallorca cathedral is a Gothic construction built from XIV to XVI century (Figure 1) in the city of Palma, Mallorca Island (Spain). Since 1931, the cathedral is classified as Cultural Heritage of National Interest. When compared with other Gothic cathedrals, it is found that its piers show an unusually large slenderness ratio, while its main nave span is the second longest after Girona cathedral, and its main nave among the highest ones after those of Beauvais and Milan cathedrals. The construction of the cathedral started around the year 1300. The Trinity Chapel (part A in Figure 2) was completed in year 1311 while the Royal Chapel (part B in Figure 2 ) was finished around the year 1370. It was then decided to modify the design from that of a single nave building to a three-nave one. Unfortunately, the reason behind this dramatic change is not known with certainty. The imposing main large nave and the west facade (parts C and D in Figure 2) were completed by the year 1601 [15].

The length of the nave of the main body is of $77 \mathrm{~m}$ and is distributed across seven bays, Figure 2. The width covered by the naves is $35.3 \mathrm{~m}$; the lateral nave and the central nave spans are $8.75 \mathrm{~m}$ and $17.8 \mathrm{~m}$, respectively. The lateral naves are covered by pointed vaults of simple square plan, whereas in the central nave they are of double square plan. This scheme is repeated in all the bays of the naves except in the $5^{\text {th }}$ one (from the choir), due to the presence of lateral doors. In this bay, the longitudinal span of the vaults is slightly longer. The height reached by the vaults at their highest point (the key of the transverse arches) is $43.95 \mathrm{~m}$. The cathedral is also unique in being the Gothic cathedral with the highest lateral naves $(29.4 \mathrm{~m})$. All of the octagonal columns have a circumscribed diameter of $1.7 \mathrm{~m}$ except those of the first three bays from the choir that have a slightly lesser value of $1.6 \mathrm{~m}$.

More information on the cathedral and the previous studies carried out can be found in $[16-18]$

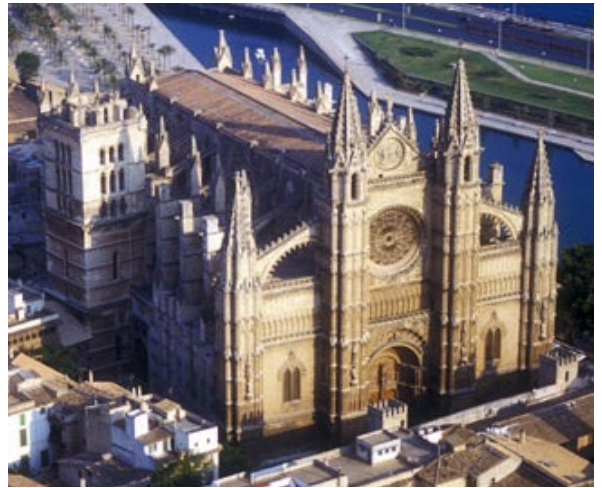

(a)

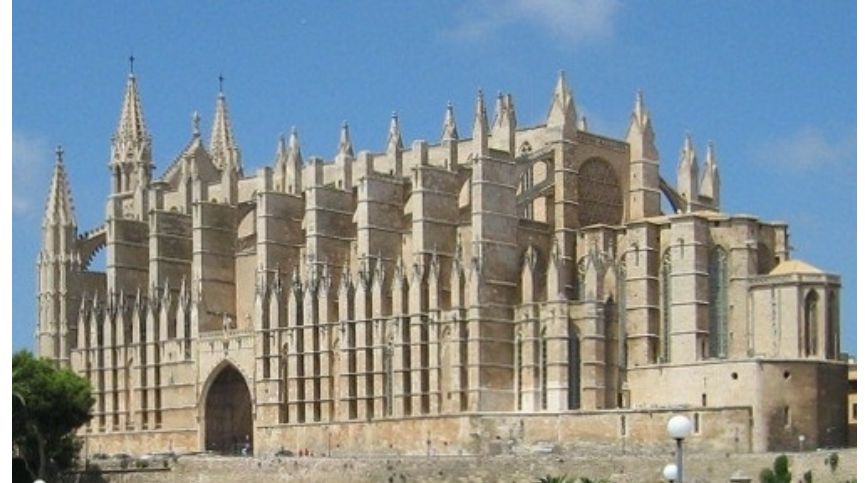

(b)

Figure 1. Mallorca Cathedral. (a) Aerial view [19], and (b) external view showing the apse area and the south façade. 


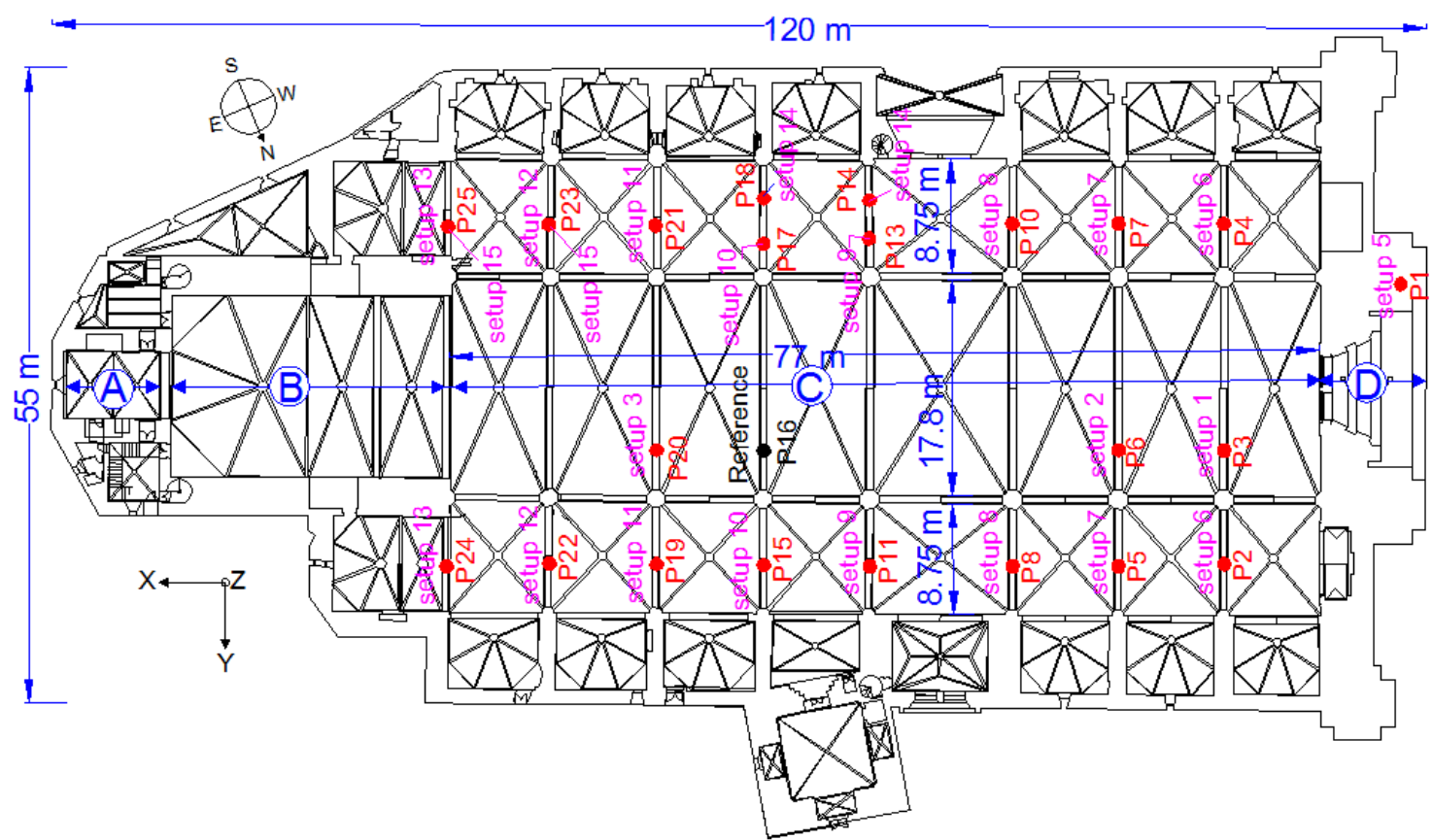

Figure 2. Plan of Mallorca cathedral showing main parts (A, B, C and D), main dimensions, and tests setups used in the dynamic identification tests.

\section{DYNAMIC IDENTIFICATION}

\subsection{Introduction}

The objective of the dynamic identification process was to gain knowledge about the global dynamic behavior of the cathedral by obtaining the modal parameters (natural frequencies, mode shapes and damping ratios) which were used for the model updating process [14], and were also compared with the results of the dynamic monitoring system.

\subsection{Tests configuration}

An important tool in the design of the dynamic identification tests was the numerical modal analysis. Via 3D finite element (FE) model, the determined mode shapes gave a good idea about which modes might be identified experimentally and which ones might be difficult to detect. Also, it helped in choosing the strategic points where to accommodate the sensors.

It was noticed from the numerical mode shapes that only the modes number 1 and 2 were global modes with considerable mass participation (Figure 3) and characterized by predominant movement of the largest body of the cathedral, i.e., the main and lateral naves [14]. All other modes were either local ones or had low mass participation. Identifying these two modes experimentally would allow defining to a very good extent the global dynamic behavior of the cathedral. Hence, and as a priority of the tests design, the sensors were organized so that capturing these modes would be achievable. Consequently, the mid span points of the central and lateral arches were chosen as the strategic points to accommodate the sensors. Those points can be simply accessed from the arches' extrados without the need for scaffolding, and were preferred to the measurements over buttresses, clerestory walls and facades. 
The chosen points for the acceleration measurement are shown in Figure 2 , and the different setups configurations are summarized in Table 1. In all setups, one sensor was kept as a reference at point 16. In the setups from 1 to 5 and the last two setups, the roving sensors were arranged longitudinally (in the longitudinal direction of the cathedral), whereas from setup 6 to setup 13, the roving sensors were arranged transversally (in the transversal direction of the cathedral). The measurement time for each setup was chosen to be not less than 1000 times the fundamental period of the cathedral. The recording time for each setup was around 15 minutes with sampling frequency of $100 \mathrm{~Hz}$. Three tri-axial force balance accelerometers were used to carry out the tests. Two of them corresponded to the CMG-5T model with dynamic range of $140 \mathrm{~dB}$ for 0.005 to $0.05 \mathrm{~Hz}$ and $127 \mathrm{~dB}$ for 3 to $30 \mathrm{~Hz}$, bandwidth ranging from $\mathrm{DC}$ to $100 \mathrm{~Hz}$, full scale from 0.1 to $4 \mathrm{~g}$, and weight of $2.7 \mathrm{Kg}$. The other one was Titan model with dynamic range of $166 \mathrm{~dB}$ for $1 \mathrm{~Hz}$ and $155 \mathrm{~dB}$ for 3 to $30 \mathrm{~Hz}$, bandwidth ranging from DC to $430 \mathrm{~Hz}$, full scale from $5 \mathrm{~V} / \mathrm{g}$ to $80 \mathrm{~V} / \mathrm{g}$, and weight of $960 \mathrm{gm}$.
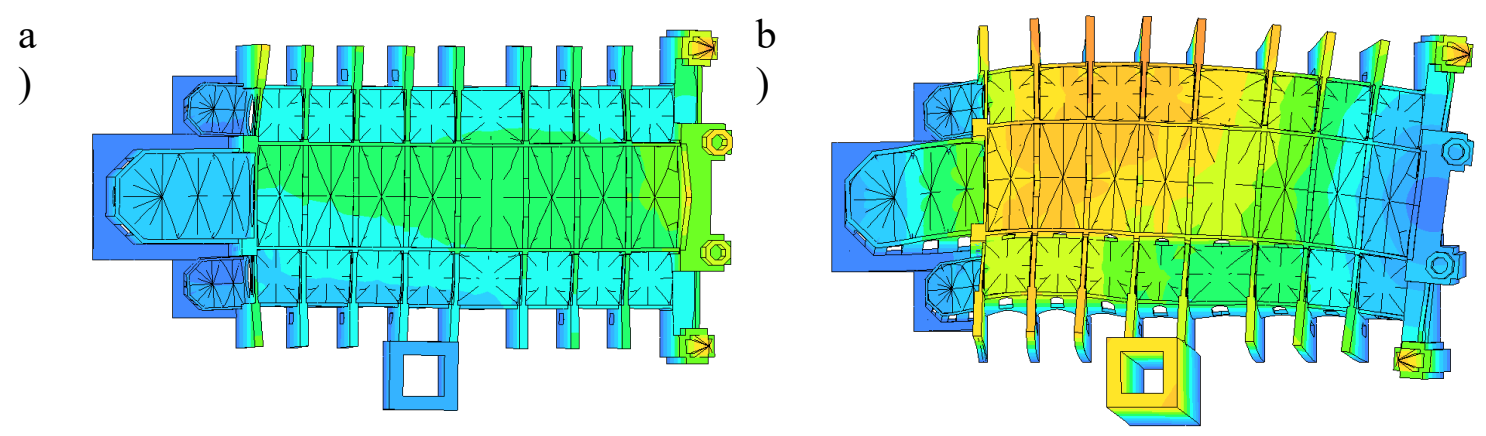

Figure 3. The first two numerical mode shapes. a) Mode 1 (60\% mass participation in the longitudinal direction) and b) mode 2 (27\% mass participation in the transversal direction).

\subsection{System identification}

For AVT, the complex non-stationary nature of the unmeasured excitation requires not only the use of robust output-only modal identification techniques, but also the validation of results through using different methods of different complexity. Therefore, the dynamic identification was carried out using multiple methods implemented in the software [20]. First, a fast estimation was performed using the Frequency Domain Decomposition (FDD) [21]. Afterwards, three more sophisticated methods were used, namely: reference-based covariance-driven Stochastic Subspace Identification (SSIcov/ref) [22], reference-based data-driven Stochastic Subspace Identification (SSIdata/ref) [22] and poly-reference Least Squares Complex Frequency domain identification (pLSCF) [23].

Using each of the aforementioned methods, each setup was processed individually, and the modes that appeared within each setup were selected. When executing this step, it was found that in each setup some modes appeared clearly while others were difficult to recognize. Accordingly, this post processing step helped in selecting the accurate combination of setups that would give the best estimation of the modal parameters for any mode. Those setups are called hereinafter "selected setups", and are resumed in Table 2. As can be noticed, the modes number 2 and 4 were found to be clearly estimated from a large number of setups. On the contrary, a mode like number 1 was not found to be clearly estimated by any setup according to three of the used techniques. More 
information about such comparisons will be given in a following section. Another objective of studying each setup individually was to judge the capability of the proposed sensors configuration in identifying the dynamic behavior of the cathedral with possible generalization to similar large historical construction.

\subsection{Comparing the results of the used methods}

\subsubsection{Natural frequencies}

Table 3 summarizes the comparison for the identified natural frequencies by all techniques. In the case of FDD, the concept of all/selected setups is not applicable since any mode can be estimated by considering only the setups that showed a peak for this mode, i.e. selected setups only. As can be noticed, the identified modes were well separated. Comparing all methods and considering all setups, the fourth mode was estimated with the same value by almost all the methods. For the other modes, it can be observed that in all cases two methods showed near results whereas the third one provided slightly different values. When comparing the selected setups set with the all setups one, a slight change in the frequency values could be observed. The mode number 4 had negligible change which stressed its accurate identification. Briefly, the different used identification methods gave near values for the natural frequencies of the identified modes whether considering all setups set or selected setups set. Thus, the estimation of the natural frequencies for all modes could be considered as reliable.

Table 3 shows a slow increase of the natural frequencies. For instance, the difference between the first and the eighth natural frequencies is of only $50 \%$. This slow natural frequency variation suggests that resonance phenomena might occur for a large range of earthquake predominant periods. This effect may contribute to the vulnerability of the structure and should be carefully taken into account in future studies oriented to the seismic assessment of the monument.

\subsubsection{Damping ratios}

The comparison between the identified damping ratios is shown in Figure 4. For all modes, the lowest damping ratio was $0,44 \%$ (mode 7 ) and the highest was $2,60 \%$ (mode 1). When comparing between the three methods considering all setups set, it can be noticed that modes number 3 and 4 had near damping ratios from all methods. Modes number 2 and 5 had two near values from two methods and a different third value from the remaining method. Comparing the case of selected setups set with the previous set of all setups, almost no changes were found in the damping values for the mode 4 , slight changes were found for mode 2 and the remaining modes showed clear changes. 


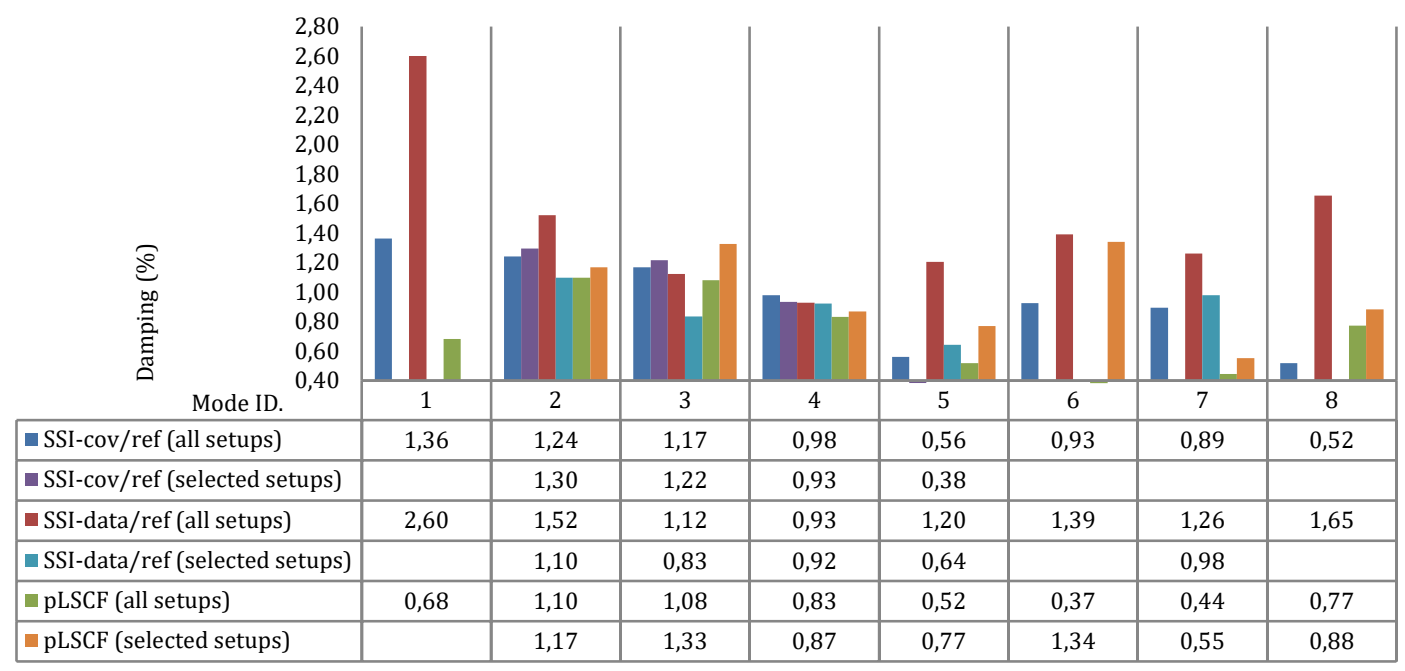

Figure 4. Comparison among identified damping ratios from different methods.

\subsubsection{Mode shapes}

It was found that the first identified mode shape was characterized by a combined longitudinal and transversal movement; however, the longitudinal movement was far more predominant. The second and the third identified modes were characterized by a pure longitudinal movement. The fourth mode was a pure transversal mode. In the fifth mode, the cathedral main nave showed a contraction-expansion movement. Both sixth and seventh modes were complex modes that showed a combination of longitudinal and transversal movements. The eighth mode was a torsional mode. The relationship between experimental and numerical modes is discussed below.

Figures 5 and 6 show the identified two global mode shapes number 2 and 4 using the method of SSI-cov/ref with a brief description. In these figures, the approximate cathedral dimensions in the longitudinal and the transversal directions are shown in the $\mathrm{X}$ and the $\mathrm{Y}$ axes, respectively. The main façade is at $\mathrm{X}=10 \mathrm{~m}$, the first frame at $\mathrm{X}=0$ and the last frame at $X=-70$. On the $Y$-axis, the cathedral center line is at $Y=0$. The main nave span is approximated to $20 \mathrm{~m}$ and the lateral nave one to $10 \mathrm{~m}$. The typical bays are numbered from 1 to 8 . For each mode, two captured views are shown to illustrate the extreme movements of the cathedral in this mode. Also, the undeformed shape is plotted in red at the background for more clarity.

The mode shapes identified from all used methods showed qualitatively some similarities and also some differences. The Modal Assurance Criteria (MAC) [24] was used to compare for each mode the identified mode shapes from all methods. Figure 7 shows the comparison among the mode shapes by the different used techniques using all setups. It should be noticed that the FDD technique identified the modes number 4, 5 and 8 in all setups. Therefore, it was possible to compare their mode shape vectors with the vectors of SSI-cov/ref, SSI-data/ref and pLSCF techniques. On the other hand, in case of the modes number 1, 2, 3, 6 and 7, the FDD identified them in some setups and therefore it was not possible to compare their vectors with the vectors of other techniques. The mode shapes of the second and the fourth modes could be trusted because the different methods identified almost the same mode shape vector. In case of mode 2 , the two MAC values of cov-data and cov-pLSCF were found to be at least 0.90 . For mode 4 , the case 
was even better, as all methods gave the same mode shape vectors with all MAC's are near 1 . The remaining modes showed scattered low values. Among them, the third mode showed acceptable MAC values between 0.80 and 0.90 from two comparisons. The remaining modes did not yield any MAC values larger than 0.80 which showed the difficulty in identifying accurately their corresponding modal shapes.

Another trial for obtaining the identified mode shape vectors was carried out using the selected setups set for each mode and compared with the previous case. Clear improvements in the MAC values were found. Figure 8 shows the case for the modes 2 and 4. Again, the fourth mode was clearly identified. The MAC index was near 1 for all comparisons between all methods for the sets of both selected setups or all setups (Figure 8 -a). The modes number 5, 6, 7 and 8 showed improvements in the MAC index when considering selected setups only. For instance, for mode 5, the MAC index using covdata pair increased from 0.57 in case of all setups to 0.80 in case of selected setups set. For modes number 2 (Figure 8-b) and 3, almost no changes in the MAC index were obtained when considering the set of selected setups.

It was noticed that the modes 1, 2 and 3 were close in shape, while modes 2 and 3 were also very close in frequency. In particular, modes 2 and 3 were purely longitudinal. The shapes of modes 2 and 3 were compared using the MAC index to reveal whether they represented in fact a single mode. When the all setups and selected setups sets were used, the MAC value was in average 0.67 and 0.79 , respectively. These quantitative comparisons showed that those two modes did not correspond to a single mode in spite of their similarity and closeness. This finding was confirmed by the dynamic monitoring system results (see section 5), in which it possible to detect simultaneously the two modes. The closeness, although not full identity, between modes 1,2 and 3 is interpreted as caused by a "breathing" phenomena induced by existing cracking. Such cracking would cause a sort of non-linearity manifested in the disassociation of modes. Specifically, a noticeable crack existing between the third and the fourth central nave bays of the cathedral might be involved in this breathing response. This understanding is consistent with the results of the vibration modal analysis carried out on the numerical model, for which a single first longitudinal mode is obtained followed by a second transverse one. According to this interpretation, the first numerical mode is associated with experimental modes 1, 2, 3 (which are disassociated due to breathing effects) while the second numerical model is associated with experimental mode 4. More details about the identified mode shapes and their relationship with the numerical ones can be found in [14]. 

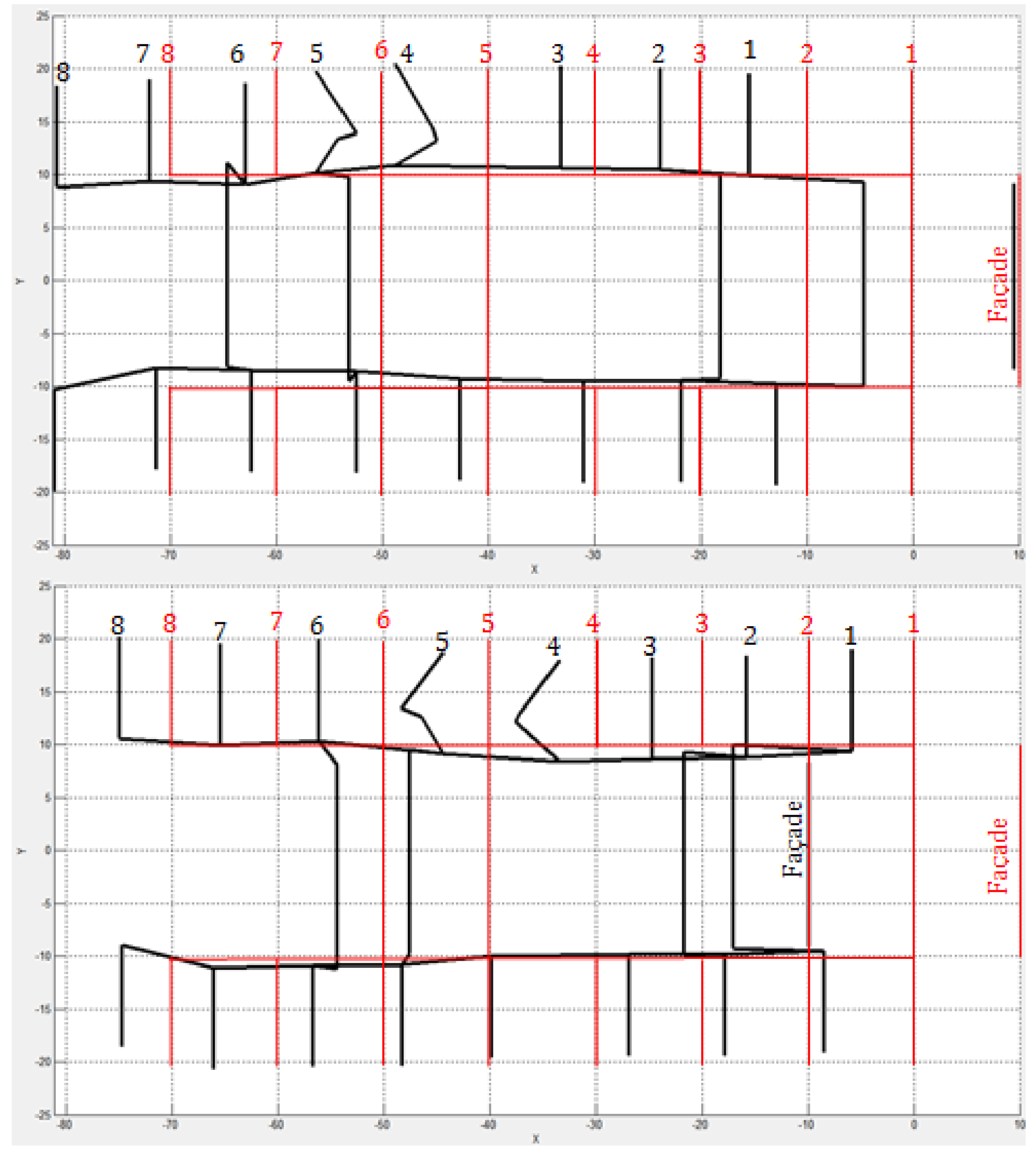

Figure 5. Mode shape 2. Longitudinal movement for the three naves. 



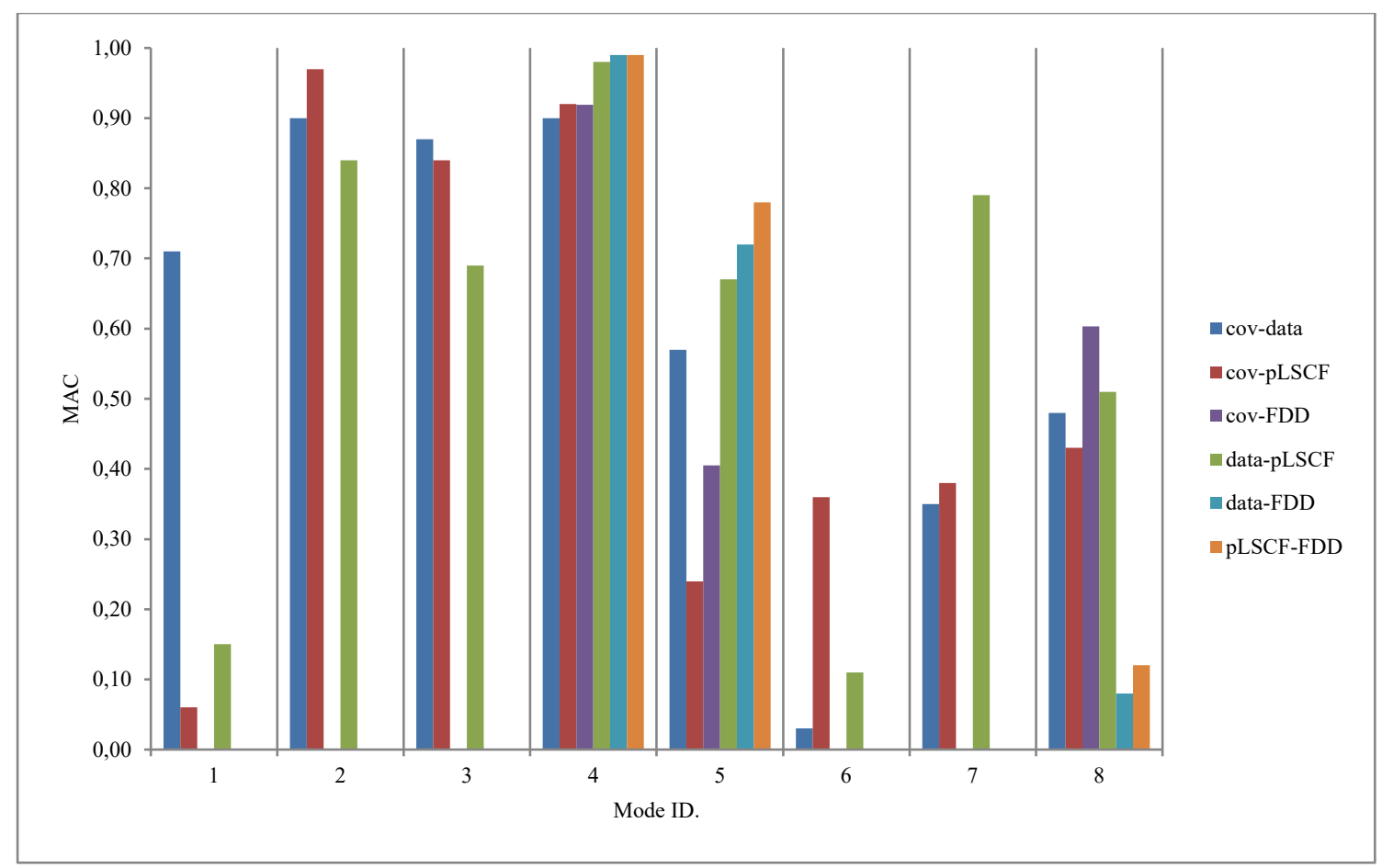

Figure 6. Comparison of MAC values among the identified mode shapes from the different methods using all setups. cov $=$ SSI-cov $/$ ref, data $=$ SSI-data $/$ ref.

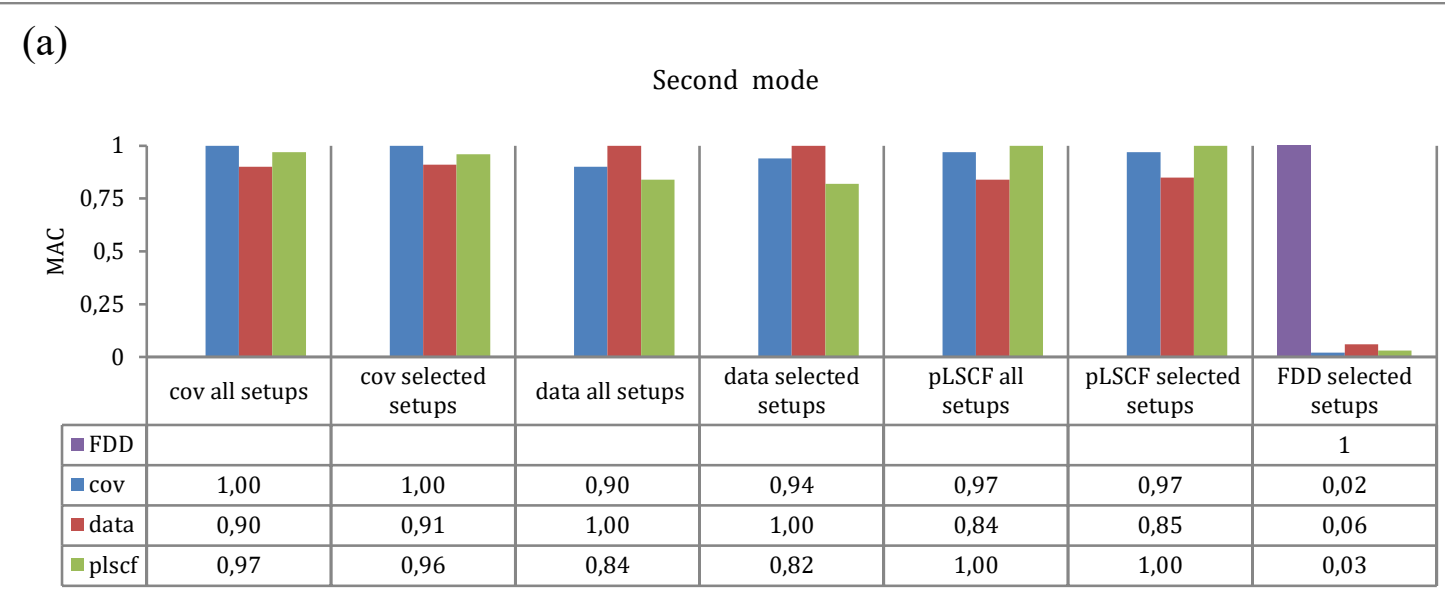

(b)

Fourth mode

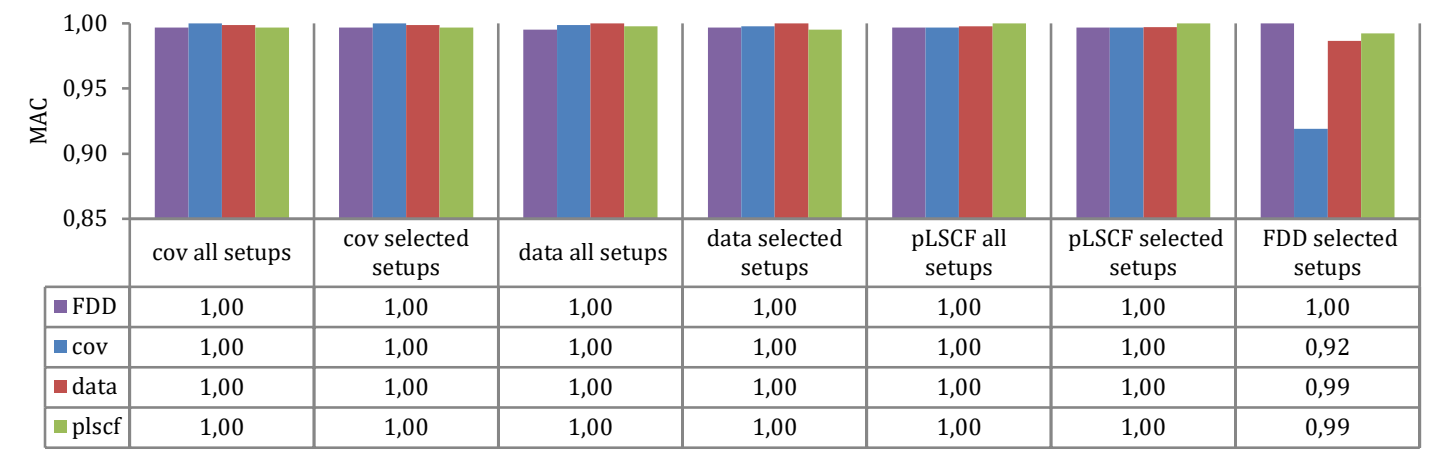

Figure 7. Comparison between the MAC index considering all setups and selected setups: (a) mode 2 and (b) mode 4 . cov $=$ SSI-cov/ref, data $=$ SSI-data/ref. 


\subsection{Evaluation of the identification process}

Regarding the efficiency of the used setups configuration in detecting the cathedral's modes, it was observed that the traverse arrangement of the roving sensors was more efficient than the longitudinal arrangement. The higher efficiency of the transverse arrangement may be due to the fact that most of the modes identified showed predominant movement in the transverse direction. In addition, the wind was blowing during the tests in the transversal direction. This finding is schematically represented in Figure 9 that compares the two arrangements. The efficiency of the longitudinal arrangement may have been affected by the placement of sensors. In the longitudinal arrangement, the sensors were not aligned along close to the buttresses and far from the center-line at the top of the roof of the building, in spite that it was along this line that the numerical model had predicted the largest longitudinal movements (Figure 2). Similar observations have been obtained in the dynamic identification of other Gothic cathedrals [7-9].

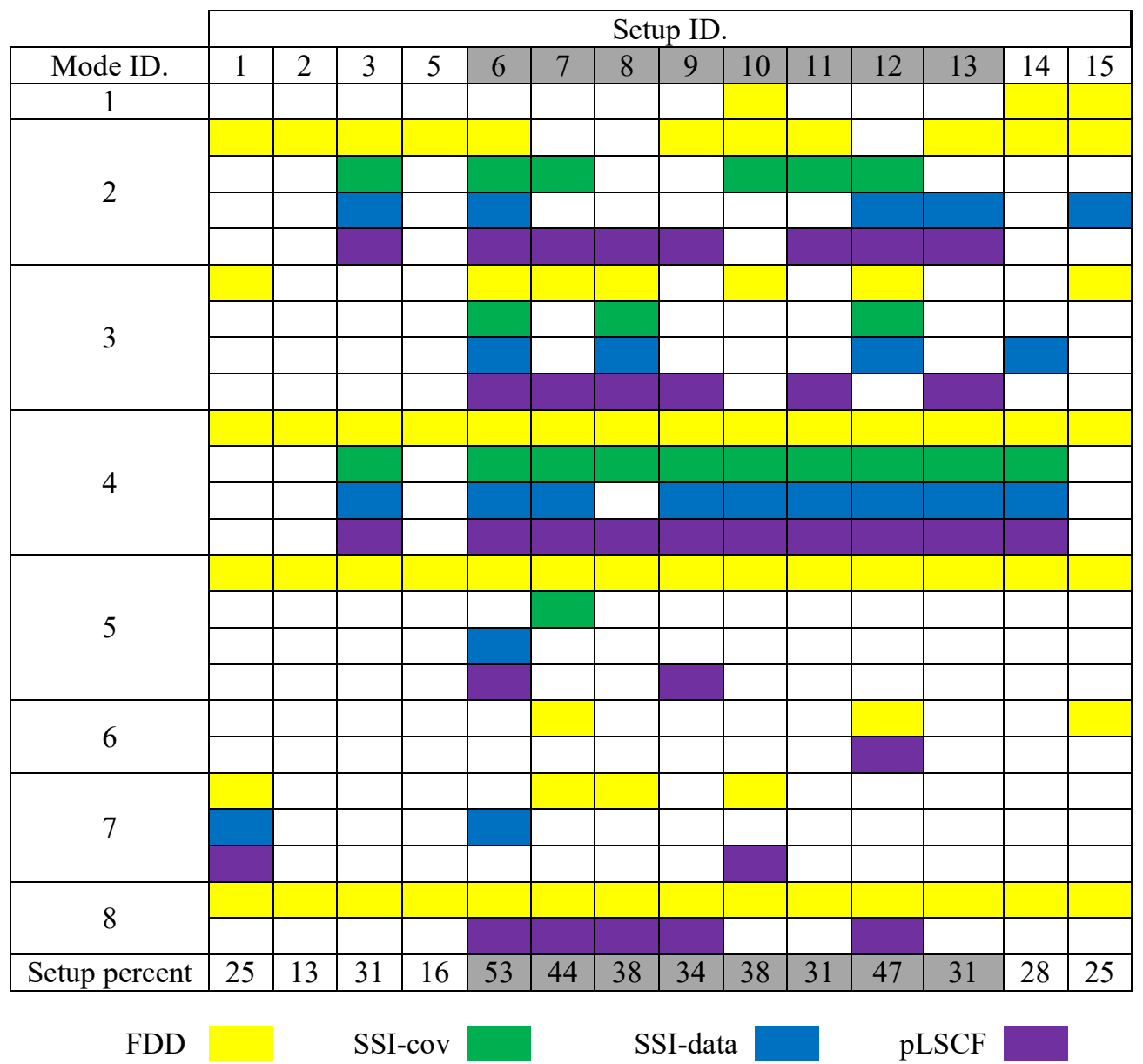

Figure 8. Graphical representation of the evaluation of the identification process: the highlighted cells represent the setups satisfactory estimated each mode using different methods. The setups from 6 to 13 are of transversally arranged roving sensors.

As can be noticed, when using an identification method, if a setup could detect a mode the corresponding cell was highlighted. Each identification method was given a different color of highlighting. The number of the used identification methods was 4 and 
the number of the total modes that could be identified was 8 , therefore each setup was given a mark out of 32 ( 4 methods $\times 8$ modes). This mark was called setup percent and is shown as a percent in the last row. For instance, setup number 1 allowed the detection of six modes using FDD, one mode using SSI-data/ref and one mode using pLSCF, this gave in total 8 which was divided by 32 to give $25 \%$.

In the first set of setups $(1,2,3,5,14$, and 15) the roving sensors were arranged longitudinally and the highest found percent was $31 \%$. In the second set of setups (from 6 to 13), the roving sensors were arranged transversally and higher percent were found.

Also from this figure, the set of selected setups for a mode (using a specific identification method) can be observed. For instance, for the mode 4 and SSI-cov/ref method, the selected setups set consisted of nines setups, those are setup number 3 and setups from 6 to 14 .

Regarding the identified modal parameters, in case of considering all setups set, close values were found for the natural frequencies from all methods. No significant changes were observed when considering the set of selected setups instead of all setups one. For the damping ratios, different values were found for most of the modes from the different used identification methods. In case of selected setups set, clear changes were also found in damping ratios compared to all setups case.

There was a clear difficulty in identifying similar mode shapes from all methods. Low MAC values were observed when comparing all methods for most of the identified modes. When considering only selected setups set, MAC values improved significantly for most of the modes.

Table 4 reports the judgment of the identified modal parameters of the cathedral. The global modes number 2,3 and 4 were the best estimated ones because from all methods whether considering all setups or selected setups it had very near modal parameters. These modes were global ones with high mass participation, which made their identification more attainable than in the case of more local ones. For the remaining modes, only their natural frequencies were satisfactory identified and the remaining modal parameters were poorly identified.

\section{DYNAMIC MONITORING}

\subsection{Description of the dynamic monitoring system}

A continuous monitoring system was used. It consisted of a system adequately equipped and programmed to continuously measure, record, and wirelessly transfer the records of the accelerations during a long period of time, on a $24 \mathrm{~h}$ basis, without having to set up an activating threshold. It was decided to implement this type of monitoring because the amplitude of the seismic motion expected in the island of Mallorca is low to moderate and may be similar in magnitude to frequent wind effects. The system was composed of a digitizer, a Data Acquisition system (DAQ), a Global Positioning System (GPS) antenna, an internet router and the three tri-axial accelerometers previously used in the dynamic identification tests. The sampling frequency was 100 samples per second.

It was decided to install two of the accelerometers on the arches of the central nave. These strategic points above arches proved its adequacy and efficiency in the dynamic identification phase, as discussed in the previous section, and therefore were chosen also for accommodating two of the three accelerometers of the monitoring system. In addition, 
those points were under a steel roof that covers the central nave. Therefore, the place was safeguarded from anthropogenic actions, direct sunlight in summer and rains in winter.

To choose the appropriate locations, a numerical modal analysis was performed using the FE model of the cathedral. The normalized modal displacements for the first ten mode shapes of the points A1-1 to A7-2 (Figure 10) were compared and those showed the largest displacements were considered for the placement of the sensors. The idea behind this comparison, on one hand, was to avoid placing the sensors above the points that had very limited or null modal displacements (nodes), and on the other hand, to place the sensors above the points that had considerable measureable movement.

Based on this comparison and as shown in Figure 10, point A2-1 was chosen to accommodate the first sensor (S1). Point A5-1 was selected to accommodate the second sensor (145 Station). A third sensor (Soil Station) was placed on the ground level of the cathedral close to the third buttress from the west façade. The system worked properly for two periods. The first period was from $17^{\text {th }}$ December 2010 to $13^{\text {th }}$ September 2011 . The second period was from $18^{\text {th }}$ May 2012 to $29^{\text {th }}$ December 2012. Within this second period, the system was interrupted from $30^{\text {th }}$ July 2012 to $4^{\text {th }}$ of September 2012.

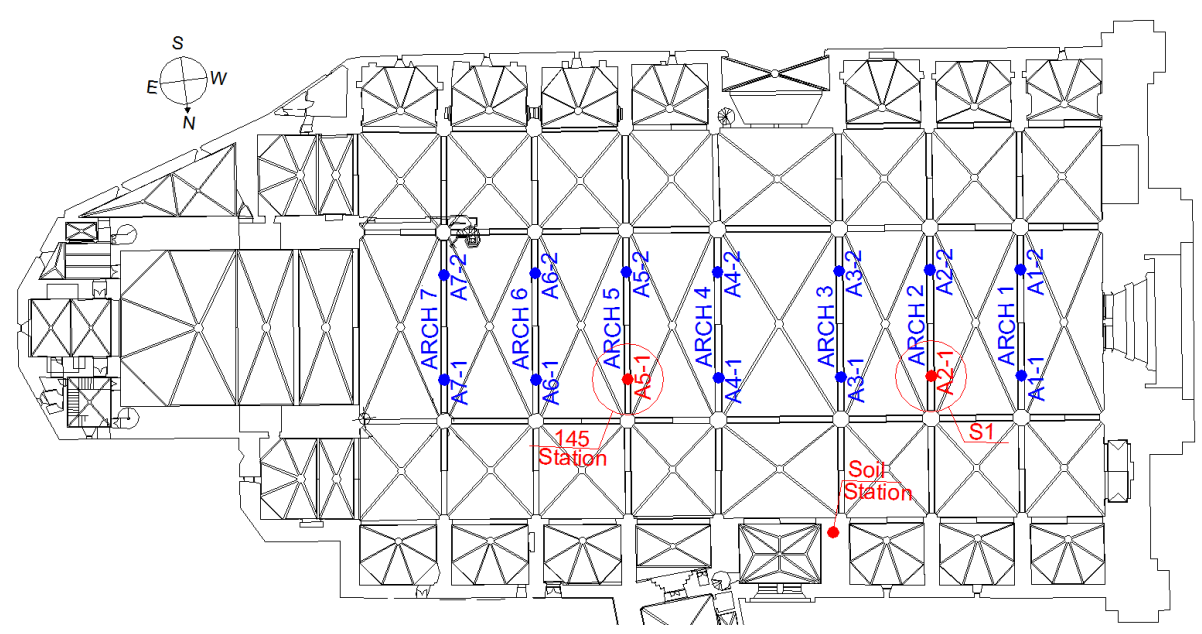

Figure 9. Investigated points for accommodating sensors (in blue) and the final chosen locations (in red).

\subsection{Data processing methodology}

The recorded data by the DAQ system was downloaded from the website of the monitoring system in files of 6 hours length. The downloaded files were in seed format and were transformed to ASCII plain data using SeisGram2K [25]. These data was used via in-house developed software to calculate the Power Spectral Density (PSD). The PSD was calculated for a signal length of half an hour with 50 seconds Hanning windows overlapped $33 \%$.

In the last step, the natural frequencies were determined manually using the Peak Picking (PP) method. The PSD calculations followed by PP were carried out four times per day: at 6 a.m. (06:00), 2 p.m. (14:00), 8 p.m. (20:00) and 12 a.m. (24:00) during the entire monitored period. This means that the frequencies were calculated each 6 hours in average so as to have a detailed image of the daily change in natural frequencies under different environmental conditions.

\subsection{Evolution of natural frequencies over time}


To present the results, the 6 channels of the two sensors were named as following: the channels 1, 2 and 3 were those of sensor 145 Station in the transversal, the longitudinal and the vertical directions, respectively; and the channels 4, 5 and 6 were those of sensor $\mathrm{S} 1$ in the same order of directions previously mentioned. Following the previously illustrated methodology, the natural frequencies were obtained from each of the six channels and then averaged. Next, the results are presented for each of the six channels first, along with the average results.

Figure 11 shows how frequently each of the natural frequencies of the first eight modes were detected by each of the six monitoring channels. The percentage of detection of any mode by any channel during the entire monitoring period was calculated from the following expression:

$$
\text { Percentage of detection }=100 \times \frac{\mathrm{N}_{\mathrm{m}}}{\mathrm{N}_{\mathrm{t}}} \quad \text { Equation } 1
$$

where, $\mathrm{N}_{\mathrm{m}}$ is the total number of appearances of the mode in all identification charts of the channel and $\mathrm{N}_{\mathrm{t}}$ is the total number of all identification charts of the channel.

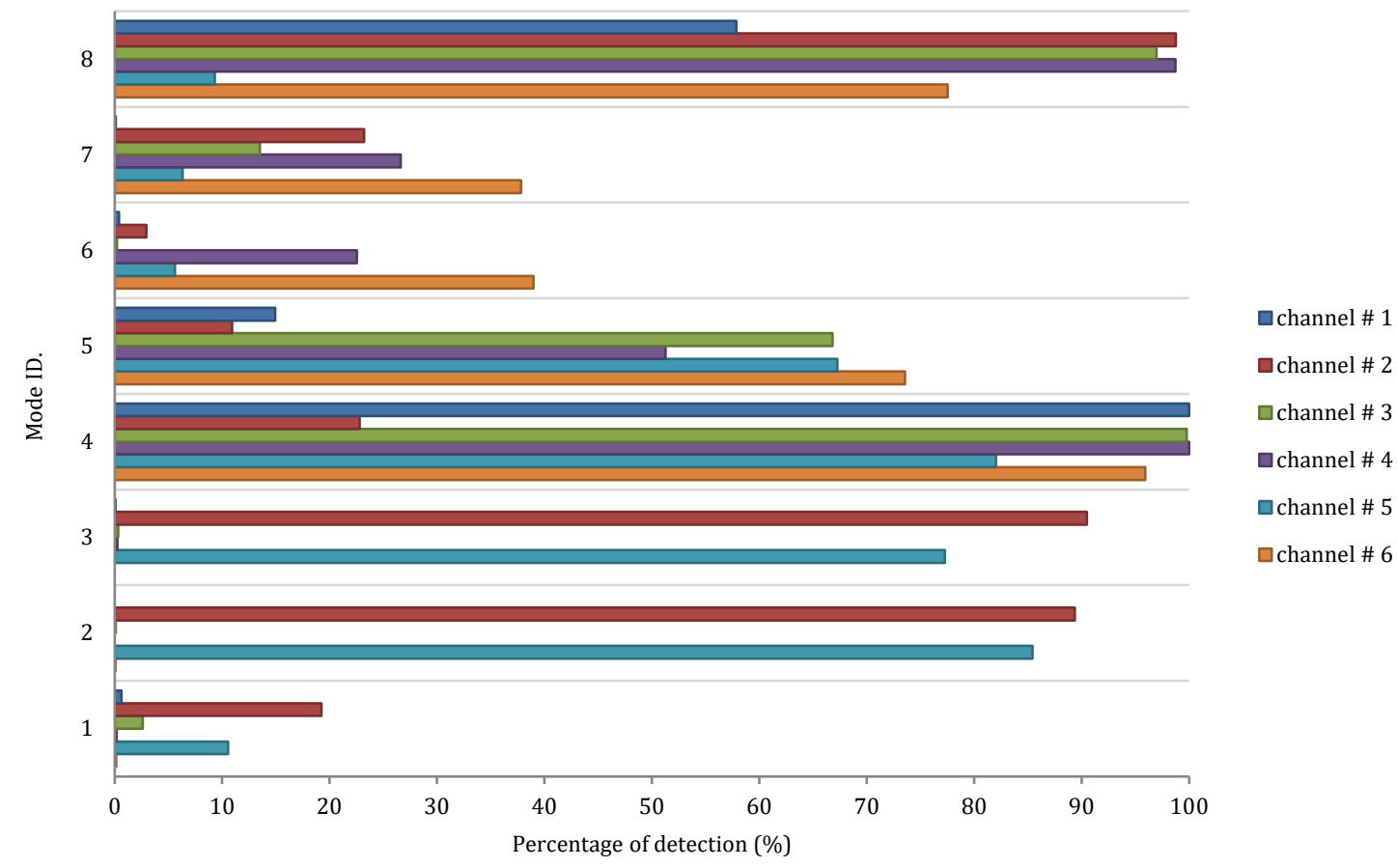

Figure 10. Percentage of detection of each mode by each channel alone.

From the figure, it can be noticed that the first mode was scarcely detected, being the maximum percentage of detection less than $20 \%$. This was also evident in the dynamic tests as it was detected in very few setups and was absent in most of the setups, and even when detected, the quality of the estimation was very low. The second and the third modes were detected very frequently; the percentage was near $90 \%$ by channel 2 and in average about $80 \%$ for channel 5 . The estimation of these modes by the dynamic tests was also satisfactory. The easy detection of the fourth mode was very obvious here. Five out of the six channels were always detecting this mode with lowest percentage of detection around $80 \%$ for channel $5,95 \%$ for channel 6 and about $100 \%$ for channels 1,3 and 4 . The fifth mode, as discussed, was a local mode and therefore it was not detected frequently. In average the percentage of detection was $65 \%$ for channels 3,5 and 6 , and even less detection percentage was found for channels 1,2 and 4 . The modes number 6 and 7 were 
local modes. Their detection was poor in all identification techniques used in the dynamic identification phase as previously discussed. Here, the difficulty of detecting these modes was confirmed. The maximum percentage of their detection was less than $40 \%$. This means that in most of the time, detecting modes 6 and 7 was not possible. The detection of the last mode, mode 8 , was satisfactorily attainable. Three channels detected this mode with a percentage of $100 \%$ while other two channels had a detection percentage of about $60 \%$ and $80 \%$.

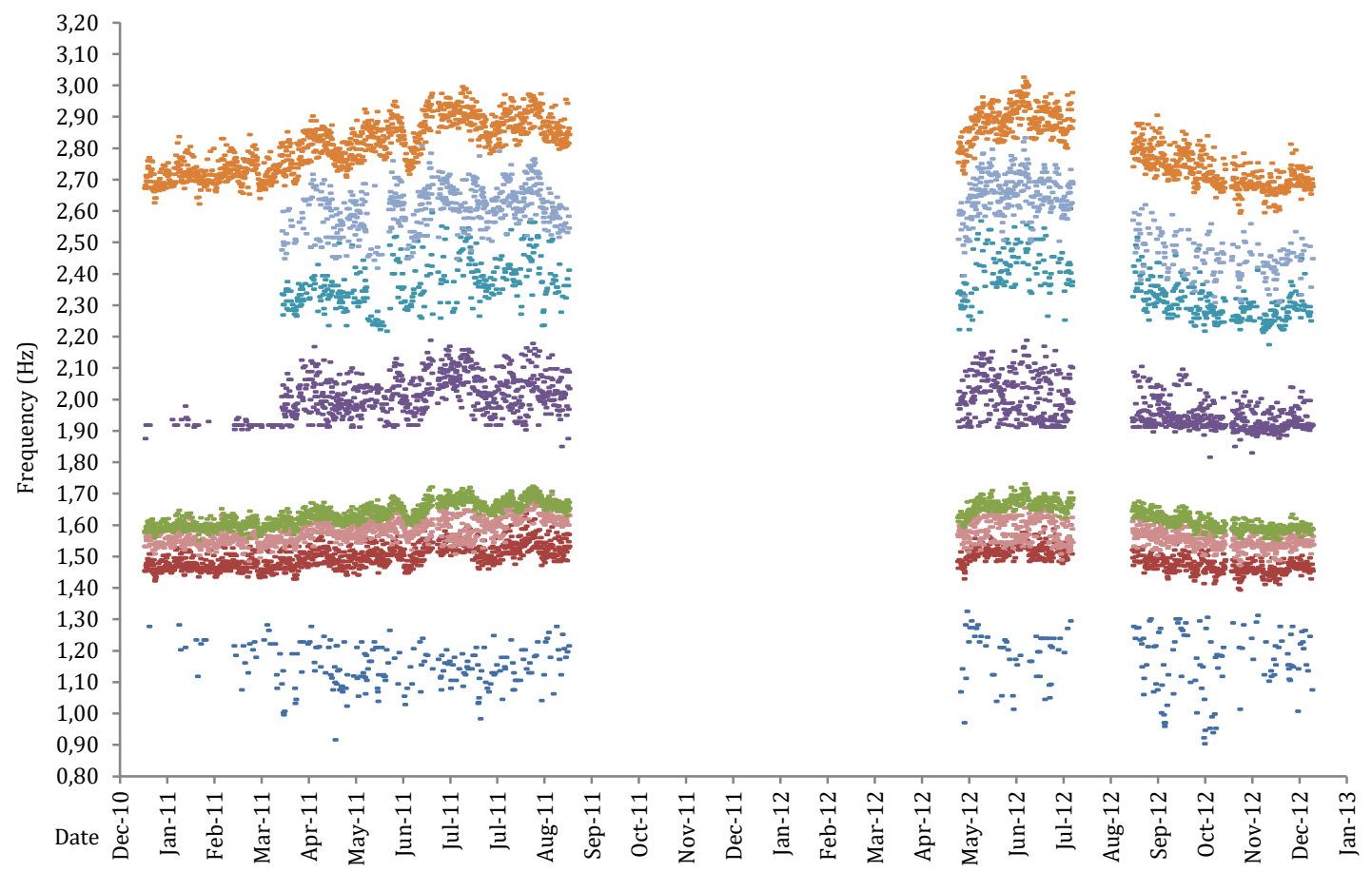

Figure 11. Evolution of the cathedral natural frequencies over time.

After obtaining the natural frequency for each mode from each channel, the average from all channels was calculated and then depicted versus the time as presented in Figure 12. The gap in the second period corresponds to the dates previously mentioned during which the system was out of service due to technical problems.

In the first monitoring period, the overall trends of the cathedral natural frequencies showed an increasing trend that can be attributed to the raising of the temperature, since the monitoring started in the winter and ended in the summer. The contrary was found for the second monitoring period during which a decreasing trend was noticed, also attributed to the temperature variations as the monitoring started in the summer and ended in the winter. The detailed effect of environmental actions on the evolution of the cathedral natural frequencies will be discussed in a following section.

It can be observed that the modes with the highest percentage of detection (modes 2, 3, 4 and 8) showed curves characterized by more continuous and intensive readings when compared to the curves of the other modes (modes 1, 5,6 and 7) that showed less continuity and intensity of readings. In addition, the curves of the modes 2, 3, 4 and 8 were less dispersed relative to the curves of other modes. The increasing and decreasing trends observed over time were more clear in the case of the continuously detected modes $(2,3,4$ and 8$)$, whereas the trends were indistinct for the remaining modes. The modes 6 and 7 were most of the time detected by channels 4, 5 and 6 (see Figure 11). 
Table 5 presents the statistical study carried out on the natural frequencies during the whole monitoring period. It compares also the results of the monitoring with those of the dynamic identification tests. The statistical study translated the qualitative appraisal of Figure 12 into quantitative values. The modes number 2, 3, 4 and 8 showed the lowest coefficient of variation $(\mathrm{CV})$. This means that the values of the natural frequencies of those modes were more centralized and manifested less variability when compared with the modes numbers 1, 5, 6, and 7 which had the highest $C V$ values. The same note can be stated when relating the range (maximum-minimum) with the maximum value as shown in the seventh column of the table. The modes $2,3,4$ and 8 had less variability than other modes. The very high value of mode 1 could be related to the difficulty of detection rather than to changes in environmental conditions.

The frequencies detected in the dynamic tests were lesser than the mean values found by the dynamic monitoring system. That is because the tests were performed in winter, whereas the monitoring system covered more months in summer than in winter. The months from May to July and also half of the month September were repeated two times in the entire monitoring period, thus resulting in an average temperature about 18,4 ${ }^{\circ} \mathrm{C}$, whereas in the tests it was of about $7,4{ }^{\circ} \mathrm{C}$.

\subsection{Effects of environmental actions on the dynamic response}

Several research results on the subject have already pointed to the measurable effects that climatic environmental actions can have over the variation of natural frequencies of a historical construction, see for instance [26-27]. Due to it, it was decided to carry out a detailed analysis of the influence of these actions on the dynamic behavior of the case study. It should be noticed that using only two sensors at the roof level was not enough to monitor the cathedral dynamic behavior in terms of changes of the mode shapes; therefore, the study was carried out taking into account only the changes in the natural frequencies. The effect of each of the important acting environmental actions (temperature, humidity and wind) on the change of natural frequencies was first studied alone. A more detailed study was performed by carrying out a multi-regression analysis between the natural frequencies and the different combinations of the aforementioned environmental actions.

\subsubsection{Effect of temperature on natural frequencies}

The change of the frequencies with temperature was plotted for the eight detected modes (Figure 13). It could be observed that the natural frequencies followed to a good extent the thermal changes over time for all modes except mode 1 . For mode 1 , the difficulty in its characterization prevented from stating clear conclusions on the effect of temperature on it. The relation was clearer and the in-phase oscillation was more evident for modes 2, 4 and 8 than for modes 3, 5, 6 and 7 .

The frequency variations under changes of exterior temperature are better illustrated when depicted versus each other and both the correlation and the regression are investigated as shown in Figure 14. As can be seen in the figure, the frequencies experience a significant increase with the temperature. This can be explained, at least in part, as caused by the closure of cracks due to the thermal expansion of the stone masonry, which results in an increase in the global stiffness. The presence of important cracks in different elements of the structure (clerestory walls, perimeter walls, buttresses) may, to some extent, explain the large influence of the temperature. Presence of micro-cracking might also significantly influence on the stiffness at the material level. In any case, the 
possible influence of other undetermined factors in the large variability of the frequencies should not be disregarded. A significant variation of natural frequencies with temperature (although normally not so large as in the present research) has been also noted by other authors having carried out dynamic monitoring in historical structures [11-12, 28-30].
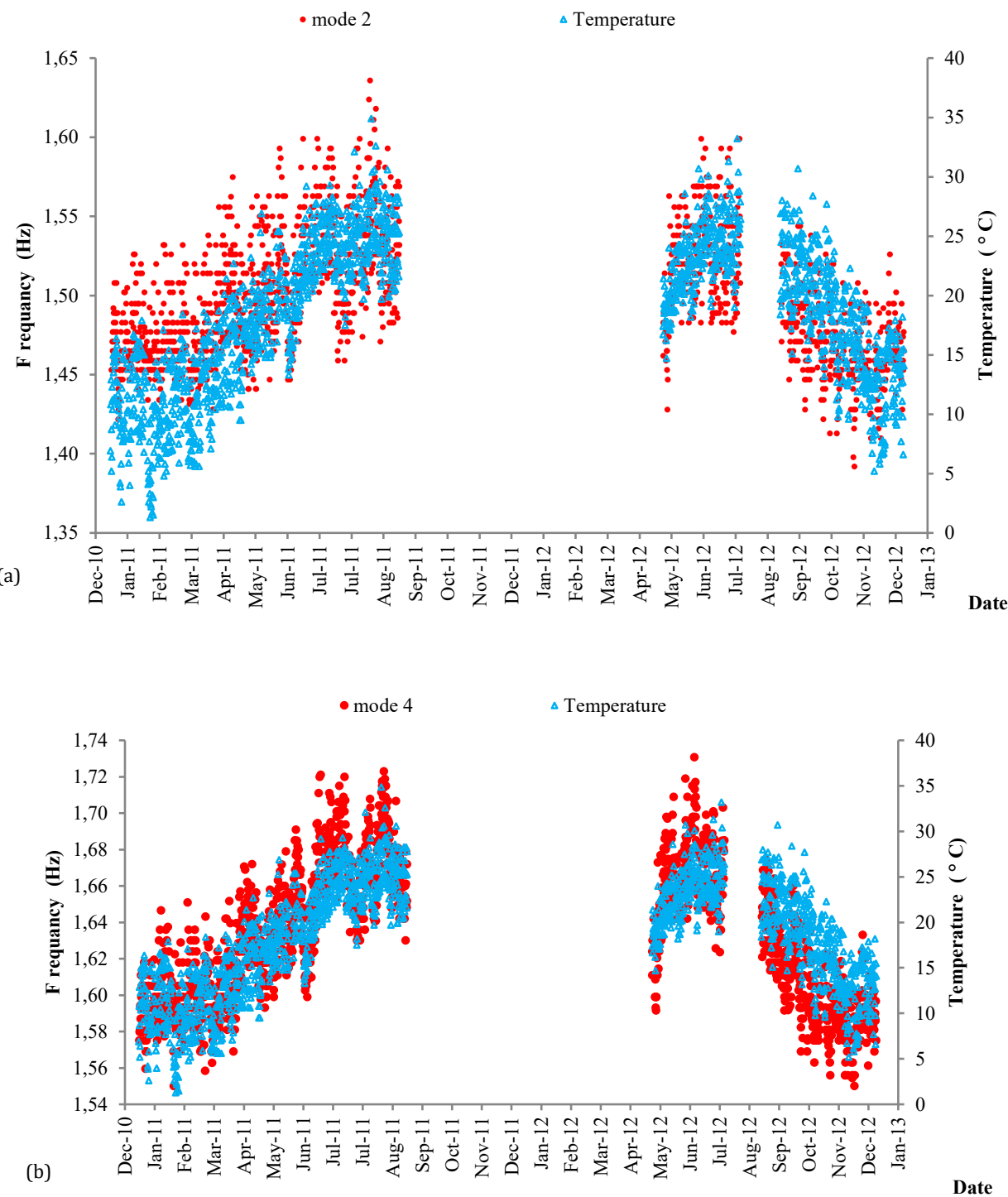

Figure 12. Changes of the frequencies with temperature: (a) mode 2, (b) mode 4. 
(a)

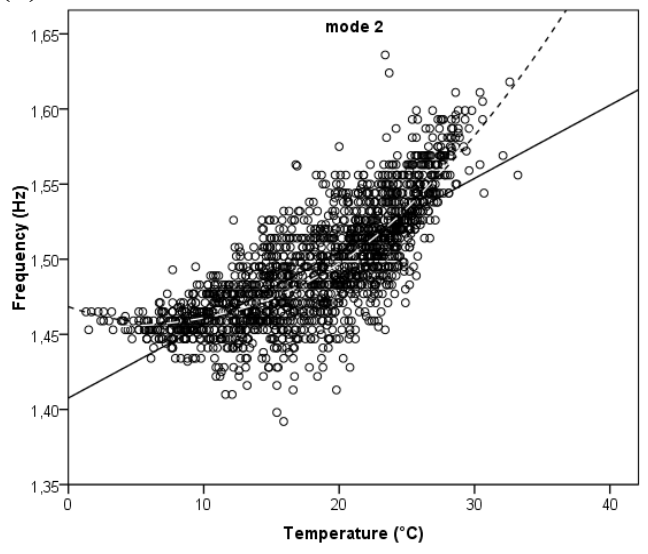

(b)

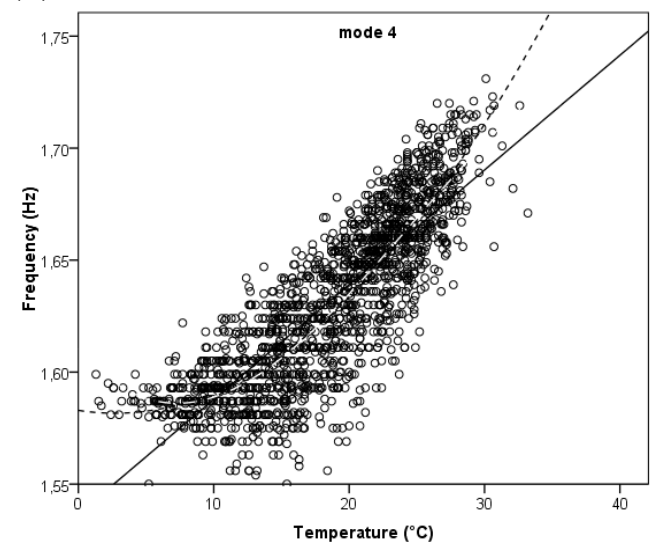

Figure 13. Correlation between temperature and natural frequency: (a) mode 2, (b) mode 4. Linear and quadratic regression models are in solid and dashed lines, respectively.

It can be noticed in Figure 14 that the trend is not exactly linear. Therefore, and considering the substantial effect of temperature on natural frequency evolution, in addition to the linear regression, the quadratic regression model was considered to investigate into more detail the type of the relation between temperature and frequencies. The obtained correlation coefficients are summarized in Table 6 . As can be seen from the comparison among all models, a linear relation between temperature and natural frequencies provided a good approximation. No significant increase in the coefficients of correlation was obtained when considering a higher degree model. The correlation coefficient of the quadratic model was only slightly higher than that of the linear one. The highest correlation value was around 0.80 to 0.86 for modes 2,4 and 8 , followed by the correlation coefficients ranging from 0.55 to 0.66 for modes $3,5,6$, and 7 . The lowest correlation was for mode 1 as previously mentioned.

\subsubsection{Effect of humidity on natural frequencies}

A negative relation between humidity and the frequencies could be noticed. For the first monitoring period, the decrease in humidity resulted from the increase in temperature and resulted in increase in the frequencies. The opposite trend could be observed for the second monitoring period. However, these trends were not clear and the influence of humidity on the natural frequencies was not as strong as for temperature. The observed negative relation might be explained by considering that the increase of humidity resulted in the increase of stone and mortar water contents which in turn increased the stone masonry mass and thus decreased the global natural frequencies of the cathedral. The correlation between the two quantities was investigated by considering three regression models linear, quadratic and cubic. A relative increase in coefficients of correlation was observed when considering nonlinear regression as can been noticed in Table 7. However, the found correlations were weak for all modes as the maximum coefficient was not more than 0.36 .

\subsubsection{Effect of wind on natural frequencies}

Figure 15 shows the frequency distributions that describe the two important parameters of wind (direction and velocity) during the entire monitoring period. The wind direction was measured as an angle from North (angle 0) to NNW (angle 337.5) in a clockwise direction, with increment angle of 22.5. As can be observed regarding the direction, the wind was blowing most of the time near to or at the transversal direction of 
the cathedral. For instance, the highest percentages of wind direction frequency distribution were about $20 \%, 14 \%, 12 \%$ in the NE, NNE and ENE, respectively. The exact orientation of the cathedral is shown in Figure 16, it can be clearly noticed that the NE direction almost coincide with the cathedral transversal direction. As for wind velocity, about half of the readings indicated calm to light wind condition according to the Beaufort scale as the velocity was in the range from 1 to $5 \mathrm{Km} / \mathrm{h}$. The other half indicated light to gentle breeze wind condition with velocity from 6 to $19 \mathrm{Km} / \mathrm{h}$. The average wind velocity was $6.7 \mathrm{Km} / \mathrm{h}$ with a standard deviation of $5.1 \mathrm{Km} / \mathrm{h}$ which reflected a high coefficient of variation of about $75 \%$.

The regression was studied between the natural frequencies of all modes with wind velocity and with wind direction adopting linear and nonlinear regression models as in the previous cases of temperature and humidity. The obtained correlation coefficients are summarized in Table 8. Considering the regression with the wind velocity, the observed correlation was weak for all modes. No correlation coefficient more than 0.35 was obtained. The modes 1 and 7 were the top correlated modes with wind velocity. The quadratic regression model was found to be slightly superior to the linear one. For the regression with the wind direction, the linear model gave the lowest correlation coefficients, while the quadratic and the cubic models gave very near results. The regression with the wind direction was also weak. The highest coefficient of correlation was obtained for mode 2 with a value about 0.45 followed by mode 5 with a value of 0.40 .

(a)

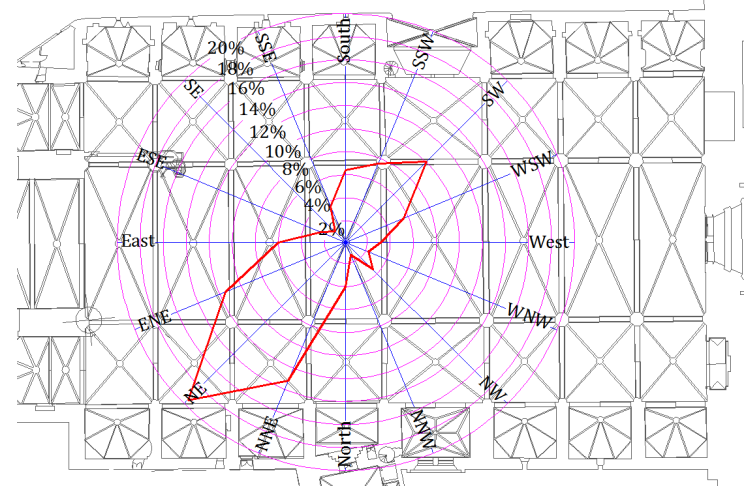

(b)

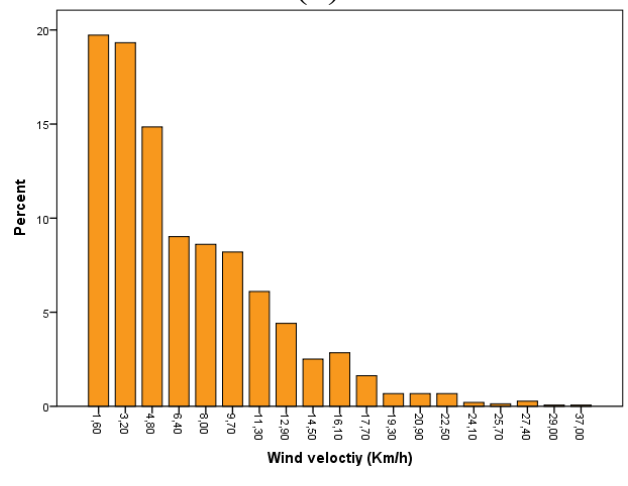

Figure 14.Frequency distribution of wind direction (a); and wind velocity (b).

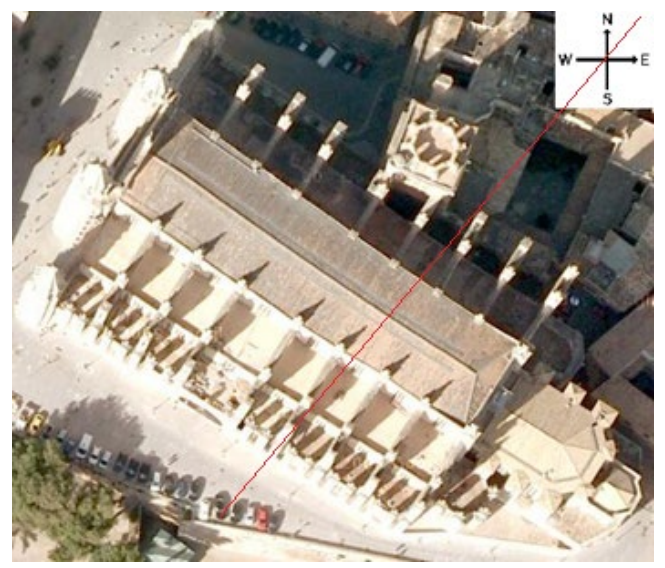


Figure 15.Exact orientation of the cathedral with respect to the main directions (adapted from Google maps). The red line points to the NE direction.

A multiple linear regression with the frequencies was carried out considering both the wind velocity and direction. Slightly higher correlation coefficients than that with the wind velocity or the wind direction were found for all modes, see last raw of Table 8 . The first mode was found to have the highest correlation coefficient with wind velocity and direction. Therefore, a more detailed investigation was carried out to reveal the dependency on wind.

The number of identifications of each mode and the corresponding percent in the entire monitoring period was investigated as shown in Figure 17. Seven modes appeared almost equally in the four times. Mode 1 was easily identified at the hour 14:00 only, whereas for the rest of the considered hours, it was rarely identified. The environmental conditions at each of the four considered times for processing the dynamic monitoring data were analyzed, as shown in Table 9. It was observed that the change in temperature and humidity was not as much as the change in wind parameters. It was found that at that hour (14:00) the wind velocity was $10.3 \mathrm{Km} / \mathrm{h}$ which was nearly the double at the rest of the monitoring hours, see Table 9. As well, the predominant wind direction was near to the south sense, whereas it was near to north sense in other times.

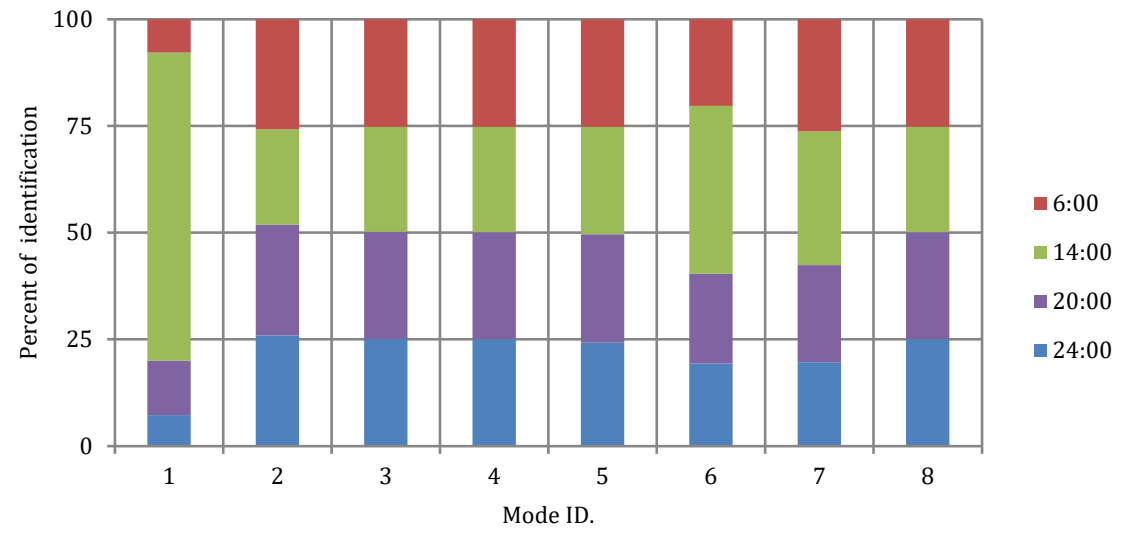

Figure 16.The percent of identification of each mode at each considered hour for processing the dynamic monitoring data.

At the hour 14:00 the wind parameters were clearly different from the other three hours. The wind velocity was nearly the double of its value. The predominant wind direction was near to the south sense, whereas it was near to north sense in other times. This further analysis at a local level of each considered hour revealed the direct dependency of the first mode detection with wind parameters. At the hour 14:00 the first mode was most of the time identifiable because of the existence of suitable wind velocity and direction as can be noticed in Figure 17. This also could be attributed to the absence of enough sensors aligned to the center-line of the cathedral where the largest longitudinal movement occurred, as previously commented.

The dependency of mode 1 on wind was further investigated. The identification of mode 1 was carried out by means of spectrograms (time-frequency distribution). The spectrogram was calculated before the hour 14:00 and continued after it for a total time 
of 12 hours. Many days were considered and here the day of $4^{\text {th }}$ June 2012 is shown as an example, Figure 18. At the time of appearance of mode 1, the average wind velocity was around $20 \mathrm{Km} / \mathrm{h}$ and the wind direction was near to SSW $\left(\right.$ angle $\left.=200^{\circ}\right)$. When the wind velocity decreased from $20 \mathrm{Km} / \mathrm{h}$ to near 0 , the peak of mode 1 disappeared, thus confirming what emerged from the entire monitoring period regarding the direct influence of wind on the detection of this mode. It was concluded that this mode correlated well with wind and was detectable only when wind was acting according to a certain direction and velocity.

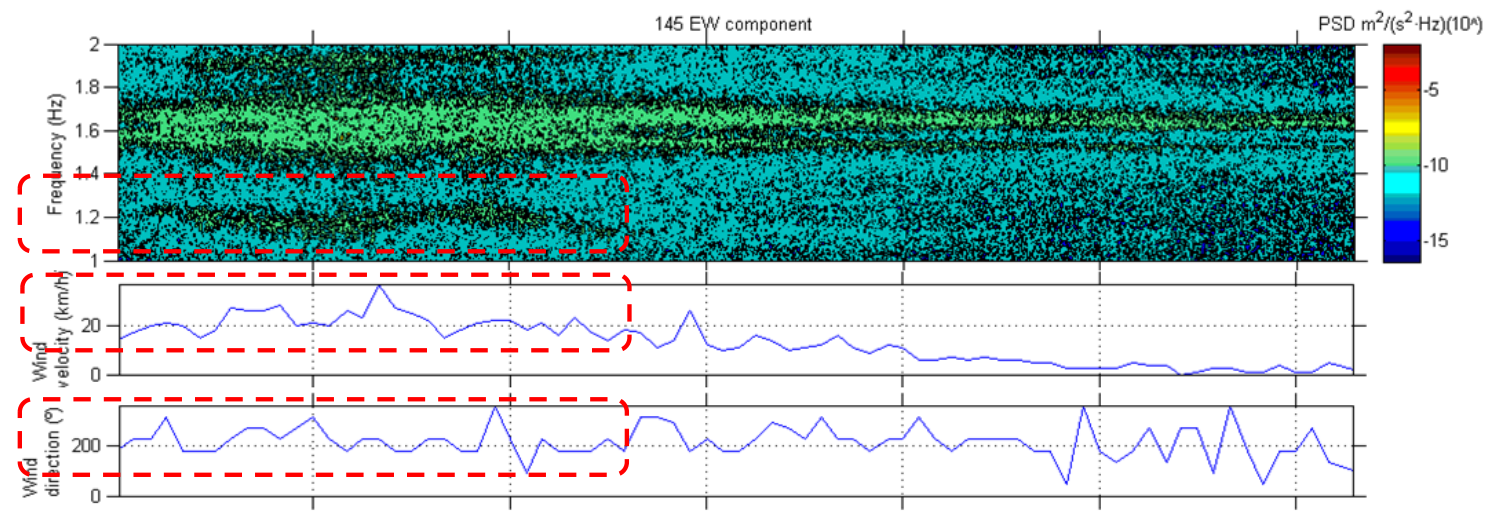

Figure 17.Twelve hours spectrogram derived from channel 2, and wind parameters at 4/6/2012. Start time at 11:00. The red windows surround the identified mode 1 and wind characteristics at that time.

\subsection{Response during recorded earthquakes}

To check the occurrence of any earthquake with significant magnitude that might produce a recordable effect to the cathedral, the website of European-Mediterranean Seismological Centre (http://www.emsc-csem.org/) was being checked periodically. In case of observing a record that was believed to be of interest, the spectrogram (timefrequency distribution) of the soil station was plotted. The spectrogram (Figure 19) can clearly show the arrival time, the frequency content and the duration of the captured seismic event.

In the post-processing of the recorded data of a seismic event of interest, the spectrogram was calculated by applying 100 seconds Hanning windows, which were considered enough to obtain appropriate frequency resolution and to avoid side lobes. Power spectral densities, coherence and two transfer function estimators (H1 and H2) for different pairs of channels (S1-Soil Station) and (145 Station-Soil Station) were computed before, during, and after the considered seismic event. If frequencies had good coherences (higher than 0,8 ) they were considered for calculations of transfer functions.

From following several seismic events, it was noticed that the regional earthquakes with magnitude about 4 , and the teleseismic earthquakes with magnitude about 8 could be detected. During the entire monitoring period, it was possible to capture one local seismic event, corresponding to the Menorca earthquake, and eight regional earthquakes with epicenter in Alagueña, Northern Algeria, Lorca, Gulf of Lion (2 events) and Northern Italy ( 3 events). Some details about captured seismic events are given in Table 10. As can be noticed, the nearest earthquake to the cathedral (Menorca) had the lowest magnitude among all recorded earthquakes. 
It was found that the captured teleseismic earthquake of Honshu arrived with low frequency content (less than 1,5 Hz), whereas the regional earthquakes had higher frequency content able to excite the range of interest of the cathedral natural frequencies, as in Figure 19 for the case of Alaguña earthquake. Table 11 compares between the measured accelerations under the effect of the ambient vibration and some of the captured seismic events. The relative gain in the measured accelerations during seismic events was evident for the case of Lorca earthquake. Other events showed less accelerations values than those registered during the windiest day.

Some effects observed in the dynamic response, even for very low amplitude motion, were attributed to the non-linear response of the cathedral. Thus, multiple close peaks appeared for the same mode in the spectral diagrams. This was perhaps due to a breathing behavior caused by existing cracks, as already mentioned in section 4.4.3. This phenomenon was noticed in mode 4 during the occurrence of the Menorca earthquake, Figures 16 and 17.

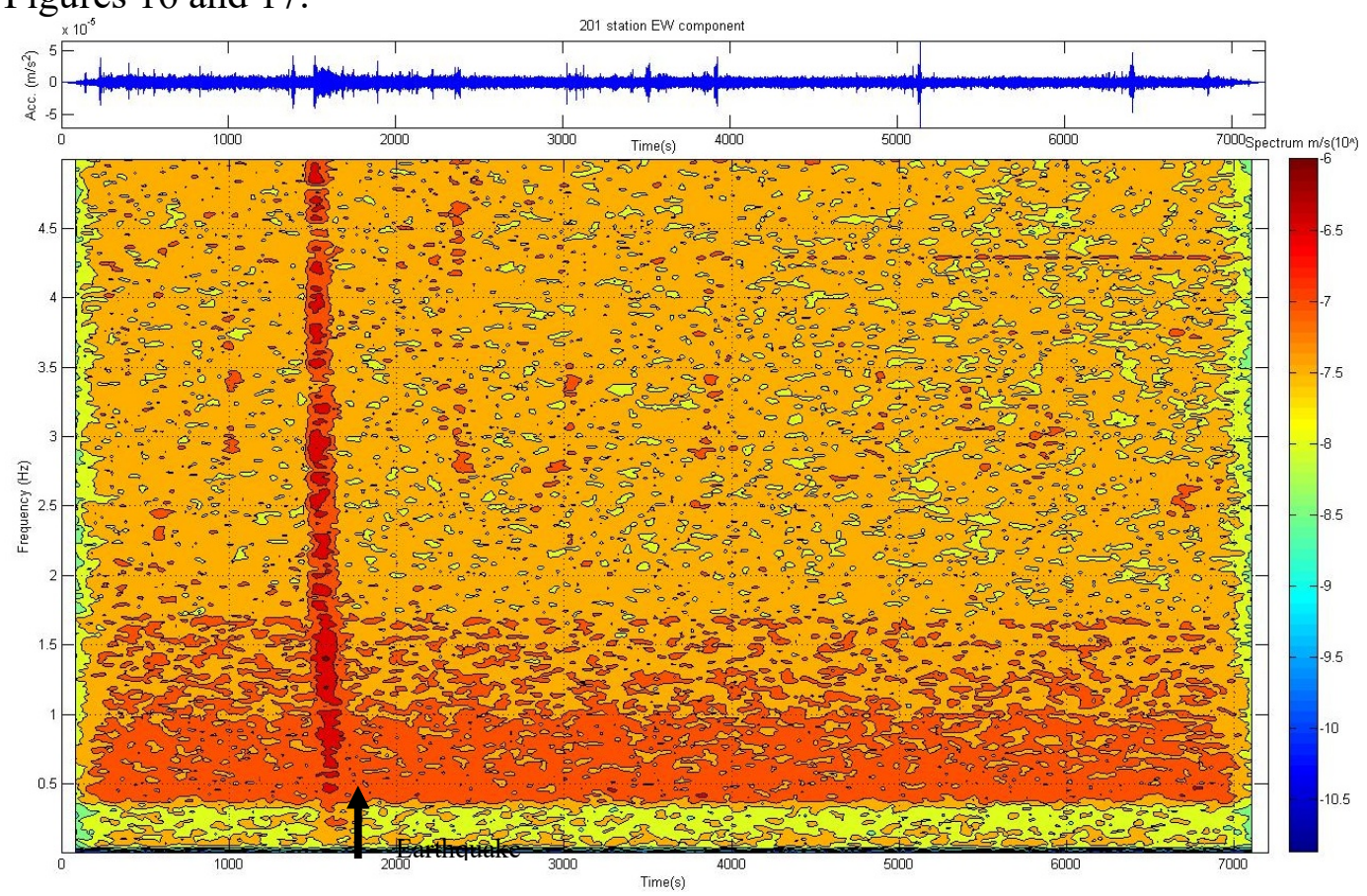

Figure 18. Spectrogram of the EW channel of Soil Station for Alagueña earthquake. Start time of the spectrogram is at 22:30:00 UTC. 

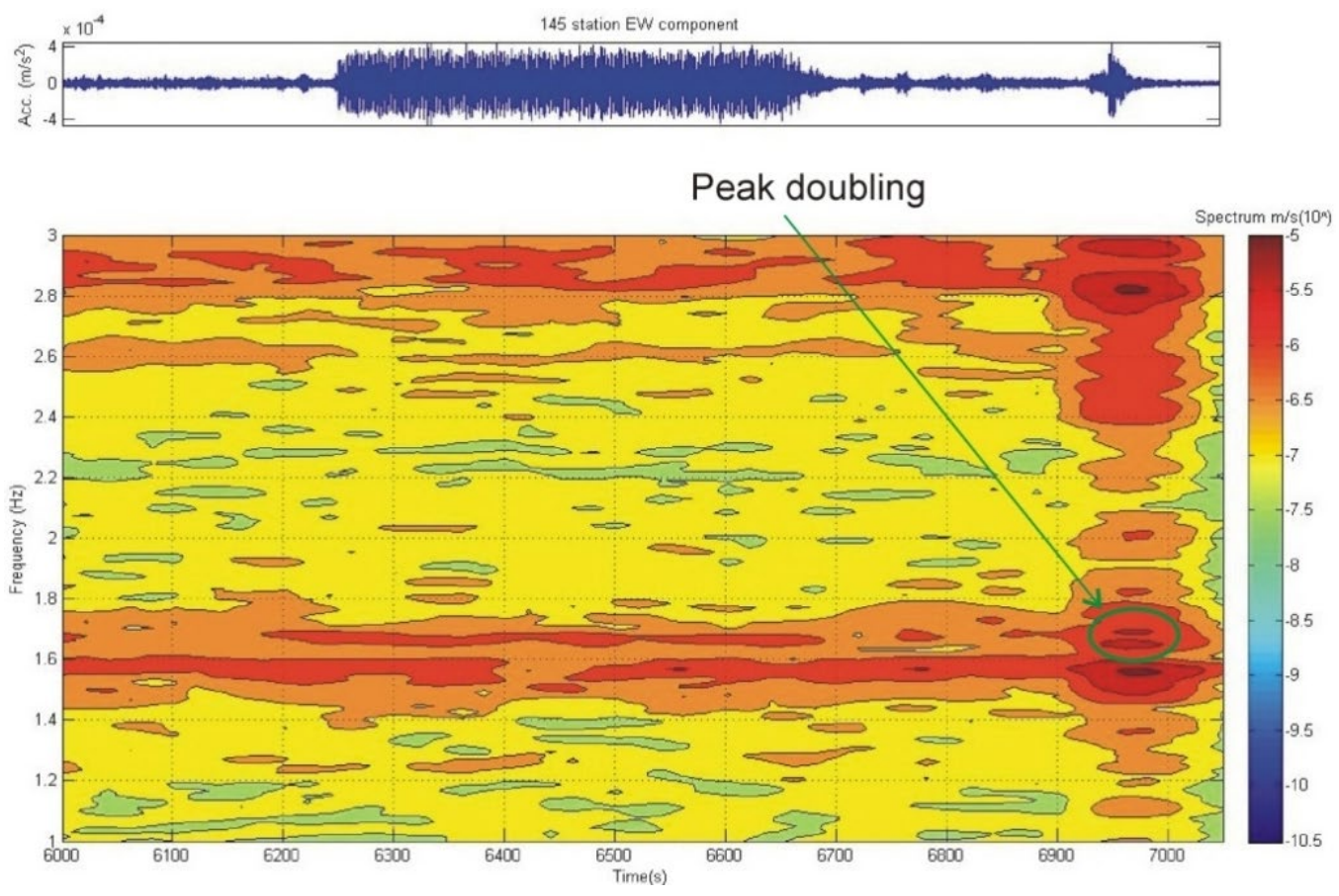

Figure 19. Spectrogram of the EW component at 145 Station for Menorca earthquake.

The breathing effect was not detected when the source of vibration was the wind, probably because the energy was delivered to the cathedral in different locations.
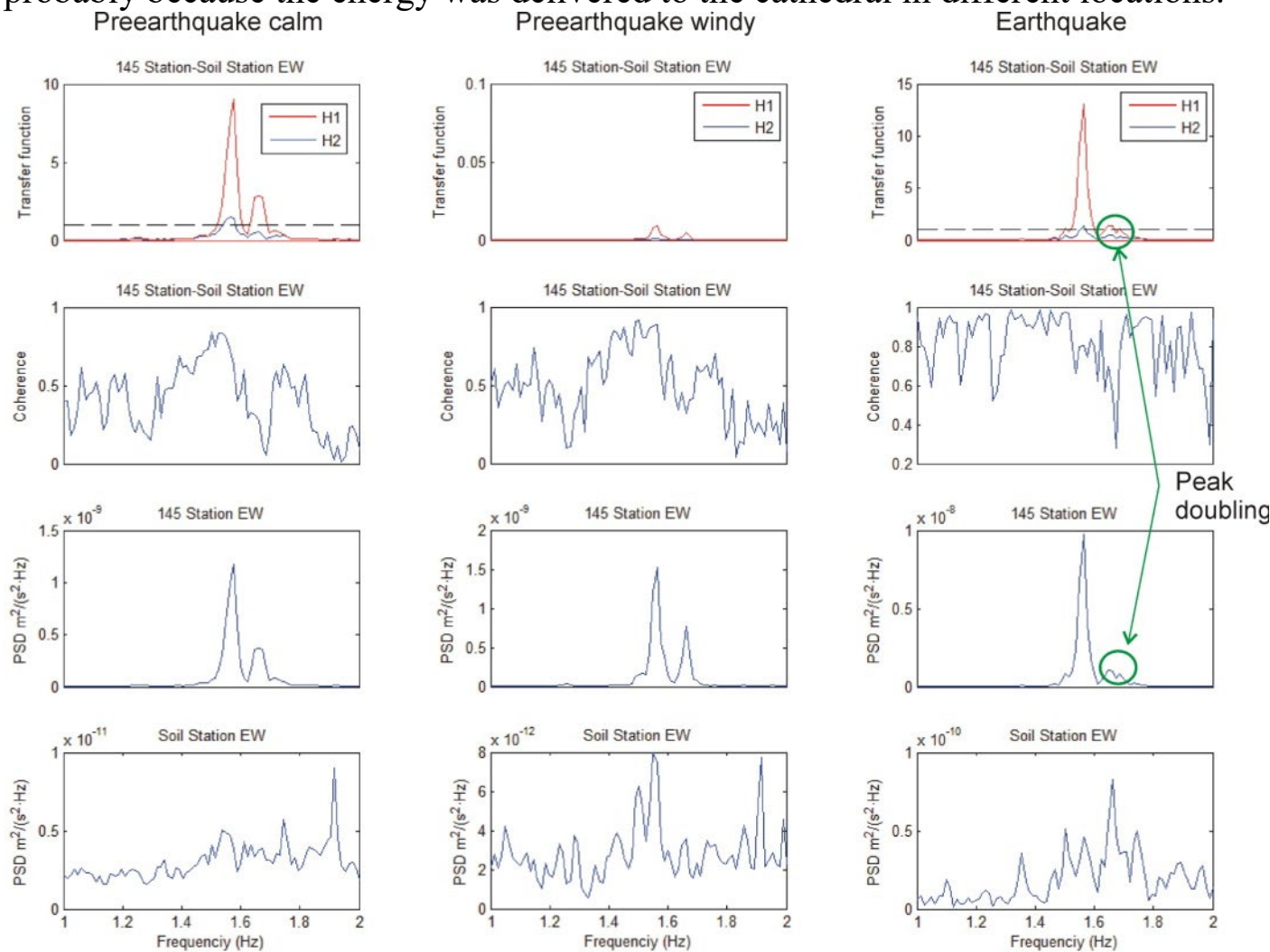

Figure 20. Transfer function and coherence of EW component between 145 Station and Soilstation and both power spectral densities for Menorca earthquake. Left: pre-earthquake with calm wind; center: pre-earthquake in windy condition; and right: during earthquake. 
At June $3^{\text {rd }} 2012$, under the effect of two consecutive earthquakes with epicenter at northern Algeria and northern Italy, the spectrogram showed a clear decrease of the frequency value (surrounded by red circles in Figure 22) of about 3\% for mode 3 . The first drop corresponded to the northern Algeria earthquake and the second drop corresponded to the northern Italy earthquake. The first noticed drop in frequency could be attributed to ambient vibration sources other than the seismic events as can be concluded from the spectrogram of soil station.

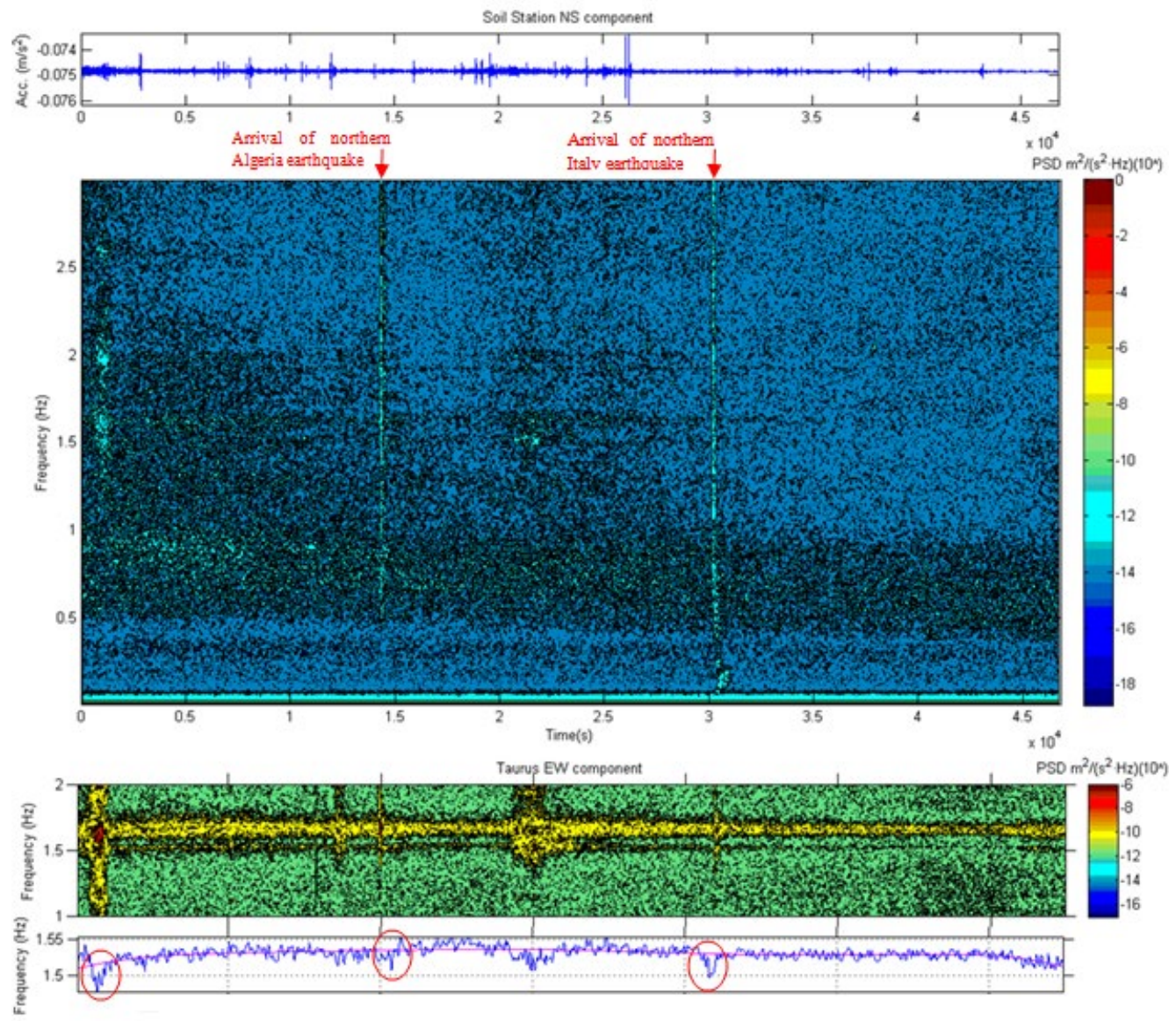

Figure 21. Processing of 13 consecutive hours of June $3^{\text {rd }} 2012$ (the start time corresponds to 11:00 UTC): top two figures: accelerogram and spectrogram of NS component of Soil-station showing the arrival of two earthquakes; and bottom two figures: spectrogram of EW component of S1-station for mode 3 with red circles on the drop of frequency.

\section{CONCLUSIONS}

This research aimed at contributing to the topic of the dynamic investigation of large historical masonry structures. The cathedral of Mallorca, an impressive medieval construction, was studied as a real case.

The dynamic identification of the cathedral was performed using AVT. Four different modal parameters identification methods were used and their results were compared. The following conclusions were drawn from the dynamic identification:

- The points near to the mid span of the arches of the main nave and the lateral naves were identified as the strategic points to accommodate the sensors. These points had considerable modal displacements. 
- The configuration of the sensors had an influence on the possibility of identifying the modes. It was noticed that more modes appeared in the setups in which the sensors were transversally arranged than those appeared when the sensors were longitudinally arranged. This can be related to the fact that most of the identified modes are characterized by predominant transverse movement. Also, it is important to note that the wind was blowing mainly in the transversal direction during tests. In fact, the identification of the first transversal mode of the cathedral was particularly eased by its excitation by wind blowing in this direction.

- It was possible to identify eight modes. The natural frequencies of all of them were satisfactory identified. However, only the mode shapes and the damping ratios of three modes were satisfactory identified. These modes were global ones with high mass participation, which made their identification easier than for more local ones.

- The identified damping ratios showed scattered values. This can be attributed to the dependency of the damping ratios with the excitation level which was low during the AVT and did not allow for a better characterization of this parameter. The damping ratios measured for the satisfactory identified modes varied between $1 \%$ and $1,5 \%$. This value is judged too low for a historical masonry structure with distributed cracks. This law value can be attributed again to the difficulty of characterizing the damping ratios under low levels of excitations.

A continuous dynamic monitoring campaign was installed for a period of more than 15 months during the years 2010, 2011 and 2012. The obtained results allowed for a detailed observation of the dynamic properties with time under environmental actions and some captured seismic events. The following main conclusions were drawn from the dynamic monitoring:

- The obtained frequencies for the eight modes under low level of excitation during the AVT were confirmed by the dynamic monitoring campaign under higher levels of excitation in the vicinity of higher wind speeds and some captured seismic events.

- The global modes of the cathedral were more detectable than the local ones because of their higher mass participation. Also, the sensors locations were chosen so that the detection of global modes could be achieved.

- For the modes from 2 to 8, temperature was a more influential environmental parameter than humidity and wind. The changes in the frequencies of these modes, in terms of CV, were between 2,3 to $3,7 \%$ and their percentual variation was between 10,4 to $18,5 \%$.

- The first longitudinal mode correlated well with wind and was detectable only when wind was acting according to a certain direction and velocity. However, this effect could be also attributed to the fact that no sensors were positioned at the center-line of the cathedral where the largest longitudinal movement occurred according to the numerical model.

- The usage of a higher cost continuous dynamic monitoring system was useful in capturing very low intensity seismic events. These events would not be detected with the usage of a lower cost triggered system. Therefore, this type of monitoring seems interesting for the dynamic identification of large buildings in low seismic zones.

- For the recorded earthquakes, it was observed a doubling of some frequency peaks. This was probably due to the breathing crack effect, i.e. the opening of the cracks that resulted in decreasing the stiffness, and therefore in; lower value of the natural frequency.

\section{ACKNOWLEDGMENTS}


This research has been carried out within the project "New Integrated Knowledge based approaches to the protection of cultural heritage from Earthquake-induced Risk-NIKER" funded by the European Commission (Grant Agreement $n^{\circ} 244123$ ), whose assistance is gratefully acknowledged.

\section{REFERENCES}

[1] Chiostrini S, Foraboschi P, Vignoli A. Structural analysis and damage evaluation of existing masonry buildings by dynamic experimentation and numerical modelling. Proc. of the 10th World Conference on Earthquake Engineering, 1992.

[2] Erdik M, Durukal E, Yuzugullu B, Beyen K, Kadakal U. Strong-motion instrumentation of Aya Sofya and the analysis of response to an earthquake of 4.8 magnitude. Proc. of the $3 r d$ Conference: Structural Repair and Maintenance of Historical Buildings III, 1993, Bath, UK.

[3] Modena C, Rossi PP, Zonta D. Static and dynamic investigation on the roman amphitheatre (Arena) in Verona. Proc., IABSE Int. Colloquium, Inspection and Monitoring of the Architectural Heritage, 1997, pp. 73-80.

[4] Diaferio M, Foti D, Giannoccaro, NI. Identification of the modal properties of a building of the Greek heritage. Key Engineering Materials 2015, 628:150-159.

[5] Foti D, Gattulli V, Potenza F. Output only identification and model updating by dynamic testing in unfavorable conditions of a seismically damaged building. Computer Aided Civil and Infrastructure Engineering 2014, 29(9), 659-675.

[6] Ceroni F, Sica S, Pecce MR, Garofano A. Evaluation of the natural vibration frequencies of a historical masonry building accounting for SSI. Soil Dynamics and Earthquake Engineering 2014, 64:95-101.

[7] Cagnan Z, Chrysostomou C Z, Kyriakides N, Votsis R. Dynamic response of a Gothic cathedral in Cyprus. Proceedings COMPDYN 2015, Paper 677, 25-27 May 2015, Crete, Greece.

[8] Votsis R A, Kyriakides N, Tantele E A, Chrysostomou, C Z. Effect of damage on the dynamic characteristics of St. Nicholas cathedral in Cyprus. In Psycharis I N, Pantazopoulou S J, Papadrakakis M (Eds.) Seismic Assessment, Behavior and Retrofit of Heritage Buildings and Monuments (pp. 281-295). Computational Methods in Applied Sciences, 2015, V. 37, Springer International Publishing.

[9] Votsis R A, Kyriakides N, Chrysostomou C Z, Tantele E A, Demetriou T. Ambient vibration testing of two masonry monuments in Cyprus. Soil Dynamics and Earthquake Engineering, 2012, 43:58-68.

[10] Rivera D, Meli R, Sánchez R, Orozco B. Evaluation of the measured seismic response of the Mexico City Cathedral. Earthquake Engineering and Structural Dynamics 2008, 37(10), 1249-1268.

[11] Lorenzoni F. Integrated methodologies based on structural health monitoring for the protection of cutural heritage buildings. 2013, PhD Thesis, University of Trento, Italy.

[12] Cabboi A. Automatic operational modal analysis: challenges and applications to historic structures and infrastructures. 2014, PhD Thesis, University of Cagliari, Italy.

[13] NCSE-02. Norma de construccion sismo resistente - Parte general y edificacion (2002) (In Spanish). 
[14] Elyamani A. Integrated monitoring and structural analysis strategies for the study of large historical construction. Application to Mallorca cathedral. 2015, PhD thesis, Technical University of Catalonia, Spain.

[15] Caselles O, Martínez G, Clapes J, Roca P, Pérez-Gracia MDLV. Application of particle motion technique to structural modal identification of heritage buildings. International Journal of Architectural Heritage 2015, 9(3):310-323.

[16] Pelà L, Bourgeois J, Roca P, Cervera M, Chiumenti M (2014). Analysis of the Effect of Provisional Ties on the Construction and Current Deformation of Mallorca Cathedral. International Journal of Architectural Heritage. DOI: 10.1080/15583058.2014.996920

[17] Roca P, Cervera M, Pelà L, Clemente R, Chiumenti M. Continuum FE models for the analysis of Mallorca Cathedral. Engineering Structures 46 (2013) 653-670

[18] Roca, P., Cervera, M., Pelà L., Clemente, R. and Chiumenti, M. 2012. Viscoelasticity and Damage Model for Creep Behavior of Historical Masonry Structures. The Open Civil Engineering Journal; 6 (Suppl 1-M7):188-199.

[19] http://asombrosaarquitectura.blogspot.com.es/2014/01/catedral-de-palma-demallorca.html.

[20] MACEC 3.2 a MATLAB Toolbox for Experimental and Operational Modal Analysis, 2011. Developed by Reynders E, De Roeck G, Copyright (C) KU Leuven, Belgium.

[21] Brincker R, Zhang L, Andersen P. Modal identification of output-only systems using frequency domain decomposition. Smart materials and structures 2001, 10(3):441-

[22] Peeters, B, De Roeck, G. Reference-based stochastic subspace identification for output-only modal analysis. Mechanical Systems and Signal Processing 1999, 13(6):855878.

[23] Peeters, B, Van der Auweraer, H. PolyMAX: a revolution in operational modal analysis. $1^{\text {st }}$ International Operational Modal Analysis Conference (IOMAC), 2005, 2627 April, Copenhagen, Denmark.

[24] Allemang RJ, Brown DL. A Correlation coefficient for modal vector Analysis. Proc. of 1st International Modal Analysis Conference (IMAC), Schenectady, New York, USA, 1982.

[25] SeisGram2K Seismogram Viewer v5.3.4X16 (10Aug2009) (BETA) Copyright (C) 2000-2009 Anthony Lomax (www.alomax.net).

[26] Lorenzoni F, Casarin F, Modena C, Caldon M, Islami K, da Porto F. Structural health monitoring of the Roman Arena of Verona, Italy. Journal of Civil Structural Health Monitoring, 2013. 3(4):227-246.

[27] Ramos, LF, Aguilar, R, Lourenço, PB, Moreira, S. Dynamic structural health monitoring of Saint Torcato church. Mechanical Systems and Signal Processing 2013, 35(1):1-15.

[28] Saisi A, Gentile C, Guidobaldi M, Cantini L. (2015). Dynamic and seismic assessment of the Gabbia tower in Mantua, Italy. In Built Heritage: Monitoring Conservation Management (pp. 141-153). Springer International Publishing.

[29] Cabboi A, Gentile C, Saisi A. Frequency tracking and F.E. model identification of a masonry tower. 5th int. Operational Modal Analysis Conf., 13-15 May 2013, Guimaraes, Portugal.

[30] Ramos L F. Damage identification on masonry structures based on vibration signatures. 2007, PhD Thesis, University of Minho, Portugal. 
Table 1.Configuration of each setup (P16 was measured in all setups).

\begin{tabular}{llllllll}
\hline Setup number & 1 & 2 & 3 & 5 & 6 & 7 & 8 \\
\hline Measured points & P3 & P6 & P20 & P1 & P2,P4 & P5,P7 & P8,P10 \\
\hline Setup number & 9 & 10 & 11 & 12 & 13 & 14 & 15 \\
\hline
\end{tabular}




\begin{tabular}{llllllll}
\hline Measured points & P11, & P15, & P19, & P22, & P24, & P14, & P23, \\
& P13 & P17 & P21 & P23 & P25 & P18 & P25 \\
\hline
\end{tabular}

Table 2. Set of "selected setups" for each mode in each identification method.

\begin{tabular}{lllllllll}
\hline & \multicolumn{10}{c}{ Mode ID. } \\
\cline { 2 - 9 } Method & 1 & 2 & 3 & 4 & 5 & 6 & 7 & 8 \\
\hline
\end{tabular}




\begin{tabular}{lllllllll}
\hline FDD & 10,14, & $1-3,5-6,9-$ & $1,6-8,10-$ & $1-3$, & $1-3$, & $7,12,15$ & $1,7-8$, & $1-3$, \\
& 15 & $11,13-15$ & 12,15 & $5-15$ & $5-15$ & & 10 & $5-15$ \\
\hline $\begin{array}{l}\text { SSI- } \\
\text { cov/ref }\end{array}$ & --- & $3,6-7$, & $6,8,12$ & $3,6-14$ & 7 & --- & --- & --- \\
\hline $\begin{array}{l}\text { SSI- } \\
\text { data/ref }\end{array}$ & --- & $\begin{array}{l}10-12 \\
\text { 3,6,12-13, }\end{array}$ & $6,8,12$, & $3,6-7$, & 6 & --- & 1,5 & --- \\
\hline pLSCF & --- & $3,6-9$, & $6-9,11,12$ & $3,6-14$ & 6,9 & 12 & 1,10 & $6-9,11$ \\
& & $11-13$ & & & & & & \\
\hline
\end{tabular}

Table 3. Identified natural frequencies (Hz) using all setups and selected setups sets.

\begin{tabular}{llllllllll}
\hline & & \multicolumn{8}{c}{ Mode ID. } \\
\cline { 2 - 9 } Method & Setups & 1 & 2 & 3 & 4 & 5 & 6 & 7 & 8 \\
\hline
\end{tabular}




\begin{tabular}{lllllllllll}
\hline FDD & selected & 1.143 & 1.431 & 1.503 & 1.569 & 1.942 & 2.232 & 2.406 & 2.649 \\
\hline $\begin{array}{l}\text { SSI- } \\
\text { cov/ref }\end{array}$ & all & 1.162 & 1.433 & 1.511 & 1.576 & 1.939 & 2.214 & 2.421 & 2.656 \\
& selected & - & 1.427 & 1.516 & 1.577 & 1.951 & & - & - & - \\
\hline $\begin{array}{l}\text { SSI- } \\
\text { data/ref }\end{array}$ & all & 1.166 & 1.445 & 1.514 & 1.576 & 1.942 & 2.241 & 2.434 & 2.662 \\
& selected & - & 1.448 & 1.512 & 1.578 & 1.951 & & - & 2.414 & \\
\hline pLSCF & all & 1.145 & 1.430 & 1.509 & 1.576 & 1.943 & 2.234 & 2.432 & 2.666 \\
& selected & - & 1.424 & 1.511 & 1.575 & 1.944 & 2.234 & 2.413 & 2.665 \\
\hline
\end{tabular}

Table 4. Judgment of the quality of identification process of Mallorca cathedral. $\mathrm{P}=$ poor, $\mathrm{G}=$ good. 


\begin{tabular}{lllllllll}
\hline & \multicolumn{10}{c}{ Mode ID. } \\
\cline { 2 - 9 } Modal parameter & 1 & 2 & 3 & 4 & 5 & 6 & 7 & 8 \\
\hline Natural frequency & $\mathrm{G}$ & $\mathrm{G}$ & $\mathrm{G}$ & $\mathrm{G}$ & $\mathrm{G}$ & $\mathrm{G}$ & $\mathrm{G}$ & $\mathrm{G}$ \\
Damping ratio & $\mathrm{P}$ & $\mathrm{G}$ & $\mathrm{G}$ & $\mathrm{G}$ & $\mathrm{P}$ & $\mathrm{P}$ & $\mathrm{P}$ & $\mathrm{P}$ \\
Mode shape & $\mathrm{P}$ & $\mathrm{G}$ & $\mathrm{G}$ & $\mathrm{G}$ & $\mathrm{P}$ & $\mathrm{P}$ & $\mathrm{P}$ & $\mathrm{P}$ \\
\hline
\end{tabular}

Table 5. Summary of statistical variation of detected natural frequencies (Hz). 


\begin{tabular}{cccccccc}
\hline $\begin{array}{c}\text { Mode } \\
\text { ID. }\end{array}$ & Min. & Mean & Max. & SD* & CV $(\%)$ & $\frac{\text { (Max. -Min. }) \%}{\text { Max. }}$ & $\begin{array}{c}\text { Dynamic tests (SSI- } \\
\text { cov/ref- all setups) }\end{array}$ \\
\hline 1 & 0.903 & 1.158 & 1.325 & 0.082 & 7.10 & 31.8 & 1.162 \\
2 & 1.392 & 1.496 & 1.636 & 0.038 & 2.57 & 14.9 & 1.433 \\
3 & 1.471 & 1.576 & 1.709 & 0.039 & 2.49 & 13.9 & 1.511 \\
4 & 1.550 & 1.631 & 1.731 & 0.037 & 2.29 & 10.4 & 1.576 \\
5 & 1.815 & 1.988 & 2.187 & 0.070 & 3.51 & 17.0 & 1.939 \\
6 & 2.173 & 2.353 & 2.606 & 0.082 & 3.48 & 16.6 & 2.214 \\
7 & 2.307 & 2.593 & 2.832 & 0.097 & 3.74 & 18.5 & 2.421 \\
8 & 2.593 & 2.797 & 3.025 & 0.089 & 3.18 & 14.3 & 2.656 \\
\hline
\end{tabular}

* Standard Deviation

Table 6. Correlation coefficients between temperature and cathedral frequencies. 


\begin{tabular}{cllllllll}
\hline & \multicolumn{8}{c}{ Mode ID. } \\
\cline { 2 - 9 } Regression model & 1 & 2 & 3 & 4 & 5 & 6 & 7 & 8 \\
\hline Linear & 0.197 & 0.766 & 0.544 & 0.834 & 0.618 & 0.640 & 0.602 & 0.806 \\
Quadratic & 0.241 & 0.802 & 0.544 & 0.854 & 0.643 & 0.660 & 0.603 & 0.819 \\
\hline
\end{tabular}

Table 7. Correlation coefficients between humidity and the frequencies (all values are negative). 


\begin{tabular}{cllllllll}
\hline & \multicolumn{8}{c}{ Mode ID. } \\
\cline { 2 - 9 } Regression model & 1 & 2 & 3 & 4 & 5 & 6 & 7 & 8 \\
\hline Linear & 0.138 & 0.292 & 0.167 & 0.276 & 0.311 & 0.158 & 0.048 & 0.293 \\
Quadratic & 0.148 & 0.332 & 0.221 & 0.336 & 0.352 & 0.164 & 0.118 & 0.349 \\
Cubic & 0.152 & 0.332 & 0.245 & 0.352 & 0.358 & 0.167 & 0.130 & 0.363 \\
\hline
\end{tabular}

Table 8. Correlation coefficients between wind velocity (WV) and wind direction (WD) and the cathedral natural frequencies. 


\begin{tabular}{llcccccccc}
\hline \multirow{2}{*}{$\begin{array}{l}\text { Regression } \\
\text { model }\end{array}$} & Wind & \multicolumn{10}{c}{ Mode ID. } \\
\cline { 3 - 10 } & parameter & 1 & 2 & 3 & 4 & 5 & 6 & 7 & 8 \\
\hline \multirow{2}{*}{ Linear } & WV & 0.292 & 0.077 & 0.141 & 0.130 & 0.164 & 0.161 & 0.329 & 0.100 \\
& WD & 0.247 & 0.134 & 0.032 & 0.019 & 0.167 & 0.003 & 0.095 & 0.032 \\
\hline \multirow{2}{*}{ Quadratic } & WV & 0.292 & 0.179 & 0.161 & 0.187 & 0.279 & 0.184 & 0.344 & 0.167 \\
& WD & 0.349 & 0.440 & 0.226 & 0.351 & 0.400 & 0.288 & 0.358 & 0.366 \\
\hline Cubic & WD & 0.354 & 0.446 & 0.228 & 0.351 & 0.404 & 0.288 & 0.361 & 0.366 \\
\hline $\begin{array}{l}\text { Multiple } \\
\text { linear }\end{array}$ & \multirow{2}{*}{ WV \& WD } & 0.389 & 0.184 & 0.140 & 0.144 & 0.205 & 0.165 & 0.329 & 0.121 \\
\hline
\end{tabular}

Table 9. Environmental conditions at each considered time for processing the dynamic monitoring data. 


\begin{tabular}{|c|c|c|c|c|}
\hline \multirow[b]{2}{*}{ Hour } & \multicolumn{2}{|c|}{ Wind } & \multirow{2}{*}{ Temperature $\left({ }^{\circ} \mathrm{C}\right)$} & \multirow{2}{*}{ Humidity (\%) } \\
\hline & Velocity $(\mathrm{Km} / \mathrm{h})$ & Predominant direction & & \\
\hline 06:00 & 5.5 & NE \& NNE & 16.4 & 46.2 \\
\hline 14:00 & 10.3 & SSW \& SW & 21.4 & 40.0 \\
\hline 20:00 & 5.4 & NE\&ENE & 18.9 & 44.4 \\
\hline 24:00 & 5.1 & NE \& NNE & 17.0 & 46.3 \\
\hline
\end{tabular}

Table 10. Details of the captured seismic events. 


\begin{tabular}{llllllll}
\hline Name & $\begin{array}{l}\text { Distance* } \\
(\mathrm{Km})\end{array}$ & $\begin{array}{l}\text { Magni- } \\
\text { tude }\end{array}$ & Date & Time (UTC) & Latitude & $\begin{array}{l}\text { Longi- } \\
\text { tude }\end{array}$ & $\begin{array}{l}\text { Depth } \\
(\mathrm{Km})\end{array}$ \\
\hline Menorca & 130 & ML 2.8 & $31-7-2011$ & $10: 55: 22.0$ & $40.20 \mathrm{~N}$ & $3.91 \mathrm{E}$ & 40 \\
$\begin{array}{l}\text { Alagueña } \\
\text { Northern }\end{array}$ & 350 & Mw 3.8 & $10-7-2011$ & $22: 54: 20.0$ & $38.34 \mathrm{~N}$ & $1.09 \mathrm{E}$ & 10 \\
$\begin{array}{l}\text { Algeria } \\
\text { Lorca }\end{array}$ & 485 & ML 4.0 & $03-6-2012$ & $14: 57: 36.0$ & $36.80 \mathrm{~N}$ & $5.20 \mathrm{E}$ & 10 \\
$\begin{array}{l}\text { Gulf of Lion } \\
\begin{array}{l}1) \\
\text { Gulf of Lion }\end{array}\end{array}$ & 493 & Mw 5.1 & $11-5-2011$ & $16: 47: 25.0$ & $37.68 \mathrm{~N}$ & $1.68 \mathrm{~W}$ & 2 \\
$\begin{array}{l}\text { (2) } \\
\text { Northern }\end{array}$ & 936 & ML 4.0 & $02-7-2011$ & $14: 43: 05.0$ & $41.98 \mathrm{~N}$ & $7.55 \mathrm{E}$ & 10 \\
$\begin{array}{l}\text { Italy (1) } \\
\text { Northern }\end{array}$ & 936 & Mw 5.3 & $07-7-2011$ & $19: 21: 48.0$ & $42.06 \mathrm{~N}$ & $7.60 \mathrm{E}$ & 10 \\
$\begin{array}{l}\text { Italy (2) } \\
\text { Northern }\end{array}$ & 936 & Mw 4.8 & $17-7-2011$ & $18: 30: 28.0$ & $45.03 \mathrm{~N}$ & $11.30 \mathrm{E}$ & 8 \\
$\begin{array}{l}\text { Italy (3) } \\
\text { Honshu }\end{array}$ & 10440 & Mw 4.3 & $25-7-2011$ & $12: 31: 20.0$ & $44.98 \mathrm{~N}$ & $7.28 \mathrm{E}$ & 25 \\
\hline
\end{tabular}

* To cathedral

Table 11. Comparison between recorded accelerations (mg) under different conditions. 


\begin{tabular}{|c|c|c|c|c|c|}
\hline \multirow[b]{2}{*}{ Condition } & & & \multicolumn{3}{|c|}{ Direction } \\
\hline & & & NS & EW & Vertical \\
\hline Dynamic tests & & & 167 & 212 & 133 \\
\hline \multirow{11}{*}{$\begin{array}{l}\text { Dynamic } \\
\text { monitoring }\end{array}$} & Ambient vibration & Windy day** & 196 & 278 & 238 \\
\hline & \multirow{10}{*}{$\begin{array}{l}\text { Captured seismic } \\
\text { events }\end{array}$} & Menorca & 41 & 41 & 34 \\
\hline & & Alagueña & 13 & 14 & 12 \\
\hline & & Northern Algeria & 10 & 13 & 11 \\
\hline & & Lorca & 181 & 85 & 79 \\
\hline & & Gulf of Lion (1) & 70 & 54 & 52 \\
\hline & & Gulf of Lion (2) & 14 & 14 & 19 \\
\hline & & Northern Italy (1) & 21 & 81 & 99 \\
\hline & & Northern Italy (2) & 21 & 27 & 31 \\
\hline & & Northern Italy (3) & 16 & 14 & 21 \\
\hline & & Honshu & 24 & 42 & 44 \\
\hline
\end{tabular}

* maximum of RMS of all channels.

** 28/9/2012 at 14:00, wind speed $29 \mathrm{Km} / \mathrm{h}$. 